\title{
Water vapor observations up to the lower stratosphere through the Raman lidar during the Maïdo Lidar Calibration Campaign
}

\author{
D. Dionisi ${ }^{1,2}$, P. Keckhut ${ }^{1}$, Y. Courcoux ${ }^{1}$, A. Hauchecorne ${ }^{1}$, J. Porteneuve ${ }^{1}$, J. L. Baray ${ }^{3}$, J. Leclair de Bellevue ${ }^{4}$, \\ H. Vérèmes ${ }^{4,5}$, F. Gabarrot ${ }^{5}$, G. Payen ${ }^{4,5}$, R. Decoupes ${ }^{4,5}$, and J. P. Cammas ${ }^{4,5}$ \\ ${ }^{1}$ Laboratoire ATmosphères, Milieux, Observations Spatiales-IPSL, UMR8190, CNRS/INSU, UVSQ-UPMC, \\ UniverSud Paris, Guyancourt, France \\ ${ }^{2}$ Istituto di Scienze dell' Atmosfera e del Clima, Consiglio Nazionale delle Ricerche, Rome, Italy \\ ${ }^{3}$ LaMP (Laboratoire de Météorologie Physique), UMR6016, Observatoire de Physique du Globe de Clermont-Ferrand, \\ CNRS/INSU - Université Blaise Pascal, Clermont-Ferrand, France \\ ${ }^{4}$ LACy (Laboratoire de l'Atmosphère et des Cyclones), UMR8105, CNRS - Université de la Réunion - Météo-France, \\ St-Denis, Réunion, France \\ ${ }^{5}$ OSU-Réunion (Observatoire de Sciences de l’Univers, UMS 3365), CNRS - Université de la Réunion, \\ St-Denis, Réunion, France
}

Correspondence to: D. Dionisi (davide.dionisi@latmos.ipsl.fr)

Received: 7 July 2014 - Published in Atmos. Meas. Tech. Discuss.: 10 October 2014

Revised: 6 February 2015 - Accepted: 9 February 2015 - Published: 20 March 2015

\begin{abstract}
A new lidar system devoted to tropospheric and lower stratospheric water vapor measurements has been installed at the Maïdo altitude station facility of Réunion island, in the southern subtropics.

To evaluate the performances and the capabilities of the new system with a particular focus on UTLS (Upper Troposphere Lower Stratosphere) measurements, the Maïdo Lidar Calibration Campaign (MALICCA) was performed in April 2013.

Varying the characteristics of the transmitter and the receiver components, different system configuration scenarios were tested and possible parasite signals (fluorescent contamination, rejection) were investigated. A hybrid calibration methodology has been set up and validated to insure optimal lidar calibration stability with time. In particular, the receiver transmittance is monitored through the calibration lamp method that, at the moment, can detect transmittance variations greater than $10-15 \%$. Calibration coefficients are then calculated through the hourly values of IWV (Integrated Water Vapor) provided by the co-located GPS. The comparison between the constants derived by GPS and Vaisala RS92 radiosondes launched at Maïdo during MALICCA, points out an acceptable agreement in terms of accuracy of the mean calibration value (with a difference of approximately $2-3 \%$ ),
\end{abstract}

but a significant difference in terms of variability (14\% vs. 7-9\%, for GPS and RS92 calibration procedures, respectively).

We obtained a relatively good agreement between the lidar measurements and 15 co-located and simultaneous RS92 radiosondes. A relative difference below $10 \%$ is measured in the low and middle troposphere $(2-10 \mathrm{~km})$. The upper troposphere (up to $15 \mathrm{~km}$ ) is characterized by a larger spread (approximately $20 \%$ ), because of the increasing distance between the two sensors.

To measure water vapor in the UTLS region, nighttime and monthly water vapor profiles are presented and compared. The good agreement between the lidar monthly profile and the mean WVMR profile measured by satellite MLS (Microwave Limb Sounder) has been used as a quality control procedure of the lidar product, attesting the absence of significant wet biases and validating the calibration procedure.

Due to its performance and location, the MAIDO $\mathrm{H}_{2} \mathrm{O}$ lidar will become a reference instrument in the southern subtropics, insuring the long-term survey of the vertical distribution of water vapor. Furthermore, this system allows the investigation of several scientific themes, such as stratospheretroposphere exchange, tropospheric dynamics in the subtropics, and links between cirrus clouds and water vapor. 


\section{Introduction}

Water vapor is a crucial climate variable involved in many processes, widely determining the energy budget of our planet. It is the dominant greenhouse gas in Earth's atmosphere and its condensed forms (liquid and ice) exert a profound influence on both incoming solar and outgoing infrared radiation. The water vapor distribution in the upper troposphere (UT) and lower stratosphere (LS) is of central importance in several ways: it plays a major role in the balance of planetary radiation, it influences and responds to atmospheric motions, and it plays a key role in many aspects of UT/LS chemistry. In fact, it strongly contributes to the stratospheric radiative balance via its greenhouse effect (e.g., Kiehl and Trenberth, 1997), and is the main precursor of $\mathrm{HO}_{\mathrm{x}}$ radicals contributing to the catalytic destruction of ozone in the lower stratosphere (e.g., Wennberg et al., 1994; Osterman et al., 1997). Furthermore, the presence of cirrus clouds in the upper troposphere, highly dependent on the concentration of water vapor and the local temperature, also strongly impacts the radiative balance (Jensen et al., 1994).

Although methane oxidation is a major source of water in the stratosphere, the question of the mechanism controlling the amount of water vapor in the stratosphere still remains (Sherwood and Dessler, 2000; Kley et al., 2000; Oltmans et al., 2000). This can be partly explained through the lack of reliable water vapor observations in the tropical UTLS (Upper Troposphere Lower Stratosphere), limited to a few balloon, high altitude aircraft measurements, and remote measurements from space at altitudes that are frequently affected by the presence of cirrus clouds. Therefore, other contributors that are related to the amount of the stratospheric water vapor are under active investigation.

In order to assess long-term trends in water vapor concentrations and address the consequences of changes in UTLS water vapor amounts, significant effort has been put into the measurements of UTLS water vapor by a large number of instruments (microwave, GPS, specific sondes, radar, lidar, etc., Kämpfer, 2012). However, because of their sampling characteristics and limitations (Kley et al., 2000), it has remained very difficult to quantify the vertical distribution of water vapor up to the stratosphere (Durry and Pouchet, 2001).

One of the main shortcomings of the current radiosonde observational network is the inability to measure accurately water vapor in the UTLS. Air-based sophisticated instruments (e.g., balloon-borne frost-point hygrometers Vömel et al., 2007a, or airborne UTLS DIAL, Kiemle et al., 2008) have a spatial and temporal limitation due to their costs and the challenging thermodynamical conditions of UTLS. Spaceborne passive remote sensors are limited by the abundance of cirrus clouds, as well as their coarse resolution in an atmospheric region (upper troposphere) where water vapor is highly variable. On the contrary, the lidar technique can provide frequent measurements with relatively high spatial resolution.

In response to the need for accurate monitoring of UTLS water vapor trends, the Network for the Detection of Atmospheric Composition Change (NDACC) has recently included water vapor Raman lidar in its suite of long-term monitoring techniques. Raman-scattering-based lidar is a well-established observational technique that retrieves profiles of water vapor mixing ratio (WVMR) by analyzing Raman backscattered radiation from water vapor molecules (e.g., Melfi, 1969; Whiteman et al., 1992; Goldsmith et al., 1998; Sherlock et al., 1999a).

Over the past decades, Raman lidar capabilities have been successively upgraded with larger commercial laser power availability and improvements on the configuration of the systems (Sakai et al., 2007; Leblanc et al., 2008; Whiteman et al., 2010; Dinoev et al., 2013). The acceptance of the Raman lidar approach within the NDACC attests that the technique has achieved a comfortable level of maturity. In particular, to show that Raman water vapor lidars are suitable to extract long term trends, two areas of concern need to be addressed: the capability of measuring water vapor profiles in UTLS with adequate accuracy and without systematic bias and a calibration method that insures stable and repeatable coefficients.

These two issues have been recently discussed by different works, in part based on data acquired by NDACC labeled Raman lidar. In particular, preliminary results on the accuracy of Raman water vapor measurements in the UTLS have been obtained (Whiteman et al., 2011b, 2012; Leblanc et al., 2012), and different calibration methodologies have been developed (Whiteman et al., 2006; Leblanc et al., 2011; Hoareau et al., 2009; Dionisi et al., 2010; Reichardt et al., 2012, Bock et al., 2013). The aim is to set up a lidar reference network for upper-air climate observations of water vapor such as GRUAN (GCOS Reference Upper-Air Network, Immler et al., 2010).

Réunion island is a location in the tropics where the understanding of water vapor variability in UTLS is crucial for long-term monitoring, as well as for studies of physical processes. For these reasons and other requirements (e.g., sky transparency), a new altitude station facility at Réunion island $\left(21^{\circ} \mathrm{S}, 55^{\circ} \mathrm{E}\right)$, located at the Maïdo Mount at $2200 \mathrm{~m}$ above sea level, was inaugurated in October 2012 for long term atmospheric remote sensing and in situ measurements (Baray et al., 2013). The station hosts various in situ and remote sensing instruments for atmospheric measurements, including a Rayleigh-Mie-Raman (RMR) lidar.

The theoretical characteristics and the design of this system are based on the water vapor observations acquired by an existing Rayleigh lidar (Hoareau et al., 2012), installed at the Observatoire de Physique de l'Atmosphère de La Réunion (OPAR) in the city of St-Denis, near the sea level. The new lidar has been conceived with a flexible design (e.g., emitted power, wavelengths, calibration techniques) that im- 
proves its performance, overcoming the measurement issues of the older one. In fact, the primary objective is an operational system in the tropics that monitors water vapor from ground level up to the low stratosphere.

To validate the lidar facilities of the observatory, the first Maïdo Lidar Calibration Campaign (MALICCA) was held between 1 and 23 April 2013. The generalities of MALICCA are presented by the paper of Keckhut et al. (2015), while the purpose of this study is to illustrate the results of the campaign objectives for RMR-H2O lidar system:

- optimizing the lidar performances with different instrumental configurations

- characterizing the system errors and biases

- evaluating and setting up a calibration methodology

- validating the measurements through comparisons with Vaisala RS92 probes

- evaluating the lidar capabilities of measuring water vapor in UTLS down to a few ppmv.

The results of these investigations are organized as follows: in Sect. 2 the basis of the Raman lidar technique to retrieve water vapor profiles is reviewed, and the instrumental setup is described together with the characteristics of the employed ancillary instruments such as the GPS sensors and the Vaiisala RS92 radiosondes. Section 3 compares the results of different instrument configurations, along with the related bias characterizations, to those theoretically estimated by Hoareau et al. (2012). In the frame of a long-term monitoring strategy, the setup and the evaluation of the hybrid calibration approach, recommended by NDACC, are discussed in Sect. 4. The capabilities of the new system RMR-H2O system to sense UTLS region are evaluated in terms of accuracy and associated uncertainties in Sect. 5. Finally, in Sect. 6, the results and the perspectives of the water vapor monitoring through the new RMR- $\mathrm{H}_{2} \mathrm{O}$ lidar installed at the Maïdo observatory are summarized and discussed.

\section{Theory and instruments}

\subsection{Raman lidar WV profile retrieval}

Raman-scattering-based lidar for atmospheric water vapor measurements has been amply described in the literature (Mel, 1972; Sherlock et al., 1999b; Leblanc et al., 2012). However, to discuss the adopted technical solutions in the system configuration of $\mathrm{RMR}-\mathrm{H}_{2} \mathrm{O}$, it is useful to report the equation relating the water vapor mixing ratio (WVMR, $w$ in the equation) to the recorded Raman signals:

$w(z)=\frac{O_{N}}{O_{H}} \frac{\xi_{N}}{\xi_{H}} \frac{\Gamma_{N}}{\Gamma_{H}} \frac{F_{N}[T(z)]}{F_{H}[T(z)]} \frac{\mathrm{d} \sigma_{N} / \mathrm{d} \Omega}{\mathrm{d} \sigma_{H} / \mathrm{d} \Omega} \frac{N_{H}(z)}{N_{N}(z)}$.
In the following, the notation $x$ stands for the Raman wavelength of the considered atmospheric component $\left(\mathrm{N}_{2}\right.$ or $\mathrm{H}_{2} \mathrm{O}$, $N$ and $H$ in the equation, respectively); $k$ is the ratio between the molecular weight of water vapor and dry air multiplied by 0.781 (the factor expressing the constant fraction of the nitrogen molecule in dry air in the homosphere); $O_{x}$ is the overlap function of the lidar channel; $\xi_{x}$ is the total lidar receiver optical efficiency; $F_{x}[T(z)]$ is the temperature dependent term; $\mathrm{d} \sigma_{x} / \mathrm{d} \Omega$ is the Raman differential backscattering cross section; $N_{x}=S_{x}-B_{x}$ is the recorded signal $S_{x}$ at the Raman wavelength of the atmospheric component $x$, subtracted by the associated background $B_{x}$, which is computed by averaging the signal return from above $100-150 \mathrm{~km}$; $\Gamma_{x}(z)=\Gamma_{x}^{\mathrm{m}} \Gamma_{x}^{\mathrm{p}}$ is the total extinction coefficient term that is usually separated into the molecular $\left(\Gamma_{x}^{\mathrm{m}}\right)$ and the particulate $\left(\Gamma_{x}^{\mathrm{a}}\right)$ contribution.

Depending on the lidar instrument setup each multiplicative term in the Eq. (1) can have a varying impact on the WVMR measurement.

\subsection{Instrument characteristics}

Whereas the previous Raman water vapor lidar system (Baray et al., 2006; Hoareau et al., 2012) was an instrumental upgrade of the receiving optics of the existing RayleighMie lidar, the new system, deployed at the Maïdo, has been designed to simultaneously sense water vapor in the whole troposphere and low stratosphere, as well as temperature in the stratosphere and mesosphere. In particular, the measurement of water vapor in the lower stratosphere is difficult for several reasons mostly related to low signals.

1. The Raman cross-section is very low.

2. The water vapor mixing ratio decreases by as much as 3 orders of magnitude from the ground to the lower stratosphere.

3. In the tropics, the tropopause is higher than at higher latitudes.

4. At $407 \mathrm{~nm}$ there is significant ambient background even on clear, moonless nights.

The adopted technical solutions have been aimed on one hand to increase the counted numbers of backscatter photons, and on the other hand to decrease the background noise and any contaminating signals.

An important difference comes also from the location: due to the lowering of the top of the boundary layer below the observatory at night under large scale subtropical subsidence, air masses at the Maïdo mount are dissociated from local and regional sources of pollution and high water content, which, on the other hand, characterizes the coastal site of OPAR. At the Maïdo site, the number of clear sky nights is then very important, the sky background is reduced (no artificial light 


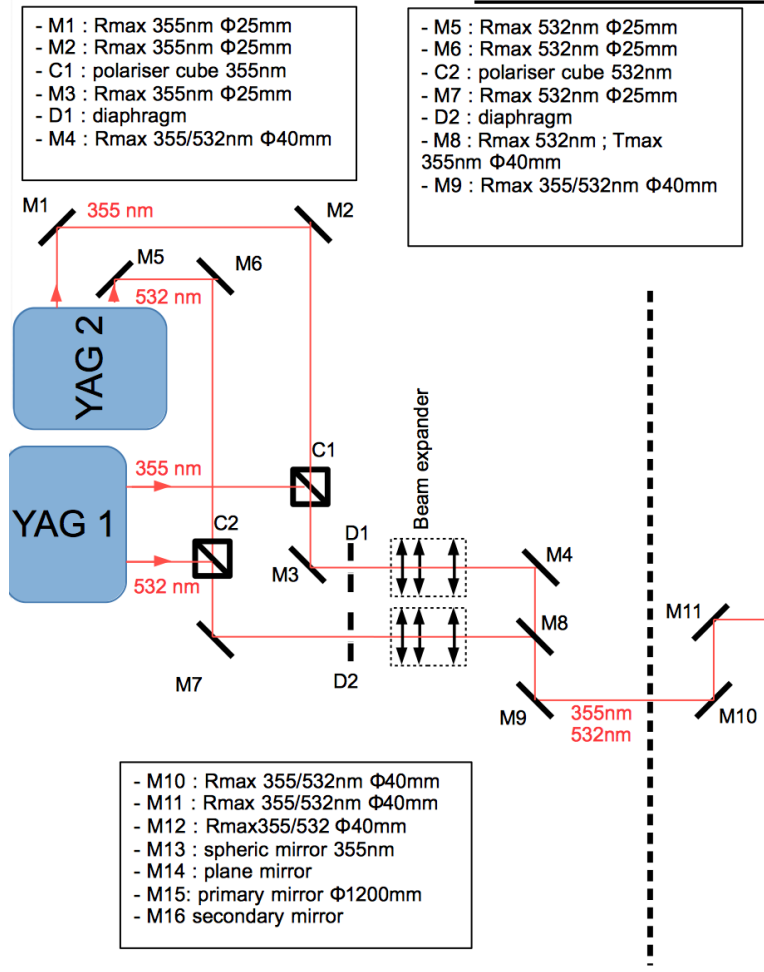

Transmitter room 6 : Rmax 532nm $\Phi 25 \mathrm{~mm}$
Lidar 1200 optical scheme

5 : Rmax 532nm Ф25mm 2 : polariser cube $532 \mathrm{~nm}$ $532 \mathrm{~nm} \Phi 25 \mathrm{~mm}$ 8 : Rmax 532nm ; Tmax . $\$ 40 \mathrm{~mm}$ 9 : Rmax 355/532nm Ф40mm$$
\text { M1 }
$$

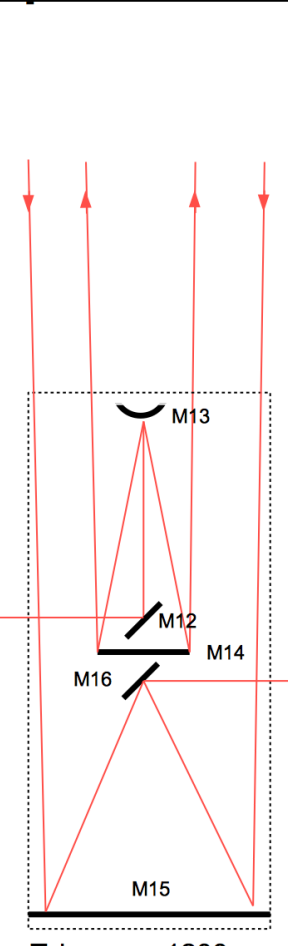

Telescope $1200 \mathrm{~mm}$
$-L 4:$ lens
- BS1 $: R>500, T<500 n m$ - BS2 : Rmax355, T>355nm - BS3 : Rmax387, T>387nm - HP-IFF1 : highpass filter $387 \mathrm{~nm}$ - HP-IFF2 : highpass filter $387 \mathrm{~nm}$ - BP-IFF1 : bandpass filter $387 \mathrm{~nm}$ - BP-IFF2 : bandpass filter $407 \mathrm{~nm}$ - BP-IFF3 : bandpass filter $355 \mathrm{~nm}$ - BS4 : beam splitter $92 / 8$ - BS5 : Rmax532, T>532nm - BS5 : Rmax532, T>532nm - BS6 : Rmax607, T>607nm - BP-IFF4 : bandpass filter $607 \mathrm{~nm}$ - BP-IFF5 : bandpass filter $660 \mathrm{~nm}$ - BS7 : beam splitter $92 / 8$

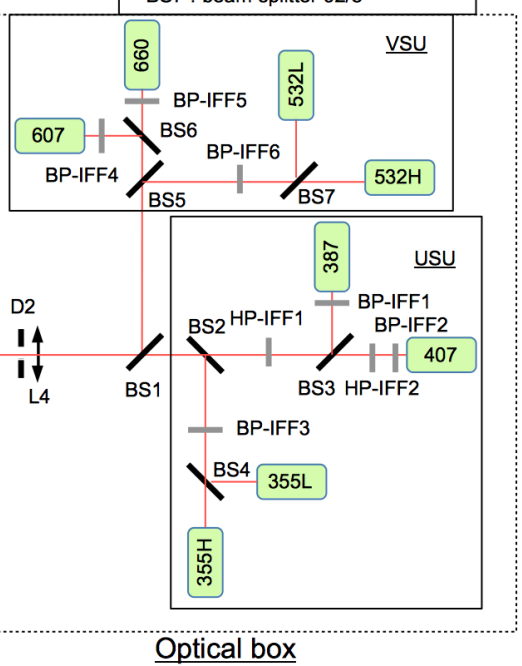

Receiver room

Figure 1. Optical scheme of the Mäido lidar. The optical components of the visible separation unit (VSU) and the UV separation unit (USU) are described in the text.

pollution from the city) and the aerosol load is negligible under typical nighttime conditions (Lesouëf et al., 2013).

The configuration as well as the global system design of the new RMR- $\mathrm{H}_{2} \mathrm{O}$ lidar is schematically represented in Fig. 1. The system is designed to work at two wavelengths depending on the requirements. The transmitter is based on two Quanta Ray Nd:YAG lasers operating either at second $(532 \mathrm{~nm}$ : green) or third $(355 \mathrm{~nm}$ : UV) harmonic or at both wavelengths simultaneously, with a repetition rate of $30 \mathrm{~Hz}$. Each emitting pulsed laser provides an energy of about 800 and $375 \mathrm{~mJ} \mathrm{pulse}^{-1}$, at 532 and $355 \mathrm{~nm}$, respectively, and a duration pulse of $9 \mathrm{~ns}$. The geometric divergence of the beam, before the expansion of the $5 \mathrm{x}$ beam expander is around $0.5 \mathrm{mrad}$ (nominal, full angle). To increase the performance of the system, pulses of both lasers were synchronized, at $30 \mathrm{~Hz}$, and coupled through polarization cubes (produced by the Rocky Mountain Instrument Co.). In fact, at the laser outputs, the beams have the same characteristics in terms of polarization, while, at the entrance of the cubes, because of the different optical path (see Fig. 1), each laser beam has a perpendicular polarization one to the other. This beam recombination enables the emitter to reach a power of $48(532 \mathrm{~nm})$ or $22.5 \mathrm{~W}(355 \mathrm{~nm})$.
Because it was difficult to ensure a beam-expander spherical mirror robust enough to simultaneously work at both wavelengths with the available laser power, it was decided to use wavelength-specific spherical mirrors relatively to the operational configuration (visible or UV). During MALICCA, pure simultaneous comparisons using both wavelengths were not possible and only the UV emitter configuration was adopted. All other optics are coated to be $R_{\max }$ at both wavelengths. The wavelength shift in the emitter configuration takes $10 \mathrm{~min}$ thanks to an easy access to this mirror.

A coaxial geometry for emission and reception has been implemented to avoid parallax effects, to extend measurement down to few meters from the ground and to facilitate the alignment. The primary mirror is a $1.2 \mathrm{~m}$ diameter telescope that was previously used at Biscarrosse for Rayleigh and Raman measurements (Hauchecorne et al., 1991) and that was refurbished in 2011. Light coming from this element is reflected by a secondary flat mirror, tilted at $45^{\circ}$, and directed to side of the telescope where an adjustable diaphragm field stop, located in the focal plane, defines the variable field of view of the system (3.0-0.5 mrad). This element is placed at the entrance of the optical box unit used to separate the Raman and Rayleigh backscattered signals. Thus, the current system uses a set of lenses and mirrors instead of opti- 
Table 1. Pass band interference filter characteristics of the Raman channels.

\begin{tabular}{lllll}
\hline & $\mathrm{N}_{2} \mathrm{Vis}$ & $\mathrm{H}_{2} \mathrm{O}$ Vis & $\mathrm{N}_{2} \mathrm{UV}$ & $\mathrm{H}_{2} \mathrm{O} \mathrm{UV}$ \\
\hline Central wavelength (nm) & 606.9 & 660.0 & 386.7 & 407.44 \\
Passband width, FWHM (nm) & 1.0 & 1.0 & 3.0 & 0.98 \\
Peak transmittance (\%) & 66 & 72 & 63 & 68 \\
\hline
\end{tabular}

cal fibers to transfer the backscattered signals to the optical ensemble. This configuration, despite a possible increase of optical losses, avoids a systematic bias in water vapor measurements due to fluorescence in fiber-optic cables.

Figure 1 indicates that backscattered radiation is first separated into the visible separation unit (VSU) and the UV separation unit (USU) by BS1. These permanently installed units split the Raman from the Rayleigh-Mie signals and have the same configuration in terms of optical path and equivalent optic elements.

Considering the USU, the filtered beam is split by another dichroic beam splitter (BS2) that reflects its $355 \mathrm{~nm}$ component toward a band pass interference filter (BP-IFF3, bandwidth $=1 \mathrm{~nm}$, maximum transmittance of $55.3 \%$ ). Subsequently, a beam splitter (BS4, $R: T=92: 8$ ) splits the $355 \mathrm{~nm}$ beam into low altitude and high altitude channels to optimize temperature measurement. The transmitted beam of BS2 is filtered by a high-pass interference filter (HP-IFF1) that has a maximum transmittance of 90 and $85 \%$ at 407 and $387 \mathrm{~nm}$, respectively, rejecting the signal at $355 \mathrm{~nm}$ (optical density $>6$ ). Then a last dichroic beam splitter (BS3) reflects the $387 \mathrm{~nm}$ component and transmits the $407 \mathrm{~nm}$ component toward their respective photomultipliers (PMTs). A BP-IFF1 is positioned in front of the N2 PMT, while a HP-IFF2 (optical density $>4$ ) and a BP-IIF2 are successively placed between the BS3 and the $\mathrm{H}_{2} \mathrm{O}$ PMT to reject the remaining $387 \mathrm{~nm}$ component and select the water vapor Raman Qbranch. The BP-IFF spectral response for the four Raman channels, are reported in Table 1. The BP-IFFs of the Raman channels were produced by the Barr Associates Co, while the HP-IFFs, the BSs and the BP-IFFs of the elastic channels were made by the Andover Corporation.

It is worth noting that two pairs of plano-convex lenses (eye-piece design) are placed in front of the photocathode, reducing spherical and chromatic aberrations. This design, and the fact that the optical path between BS3 and the two PMTs is identical, eliminates inhomogeneity on the detector surface that could generate important variations (in some cases more than $100 \%$ ) in the response system at low altitude (Whiteman et al., 1992; Nedeljkovic et al., 1993; Simeonov et al., 1999).

Regarding the photon detector, Hamamatsu R7400-03g and $-20 \mathrm{~g}$ photomultiplier tubes are used to detect the UV and Visible backscattered returns, respectively. The specific characteristics of these mini-PMTs are given in Hoareau et al. (2012).
The data-acquisition electronics consist in the use of LICEL PR 10-160 transient recorders for both lower altitude and upper altitude combination (photon-counting mode). The current set up allows the simultaneous acquisition of eight channels. The principal characteristics of the system are summarized in Table 2.

During a first experimental period between September 2012 to March 2013 in the visible configuration (see Sect. 3), we could do the following:

- validate the optical alignment procedure and the electronics (synchronization of both lasers)

- deliver first temperature profiles in the framework of NDACC

- get first water vapor measurements

- install two other lidars and get the first stratospheric and tropospheric ozone profiles.

During this period, we took time to evaluate the system sensitivity to different parameters (emitter divergence, optical shutter at entrance of the optical box, electronic shutter, noise of the PMTs).

\subsection{Radiosonde sensors and GPS receivers}

A permanent Trimble NetR9 GNSS (Global Navigation Satellite System that uses the satellite constellations of GPS, Global Positioning System, and GLONASS, GLObal Navigation Satellite System) receiver, referenced as "MAIG", has been set up at Maïdo atmospheric station facility since March 2013. This instrument, which uses a receiver that offers 440 channels for unmatched GNSS multi-constellation tracking performance, is devoted to fine time-scale integrated water vapor variability studies.

The basic GPS atmospheric product is the tropospheric delay. This quantity is a measure of the GPS signal delay that has traveled between a GPS satellite (at an altitude of $20200 \mathrm{~km}$ ) and a ground-based receiver with respect to propagation in a vacuum. The standard procedure for GPS data analysis assumes that the delay in any direction can be mapped from the delay at zenith to which a horizontal gradient is added. Three sets of parameters are then estimated during the analysis: zenith tropospheric delays (ZTDs), gradients, and post-fit residuals, which are the difference between the modeled atmosphere and the measurements. The GPS data were processed using GAMIT software package v10.32 (King and Bock, 2007), which solves the tropospheric and other parameters using a constrained least squares algorithm. The GPS network used in our typical differential simulation includes 21 other local stations mainly located around the Réunion volcano massif and about 15 stations overseas to ensure a sufficiently high numbers of baselines. The cutoff elevation angle was fixed to $10^{\circ}$. The ZTD, estimated by the software, is then split into its hydrostatic (usually called 
Table 2. Transmitter and receiver characteristics of the MAIDO$\mathrm{H}_{2} \mathrm{O}$ lidar system.

\begin{tabular}{|c|c|}
\hline & $\begin{array}{l}\text { MAIDO } \mathrm{H}_{2} \mathrm{O} \\
\left(41.8^{\circ} \mathrm{S}, 12.6^{\circ} \mathrm{E}, 2168 \text { ma.s.1. }\right)\end{array}$ \\
\hline \multicolumn{2}{|l|}{ Transmitter } \\
\hline Laser type & Nd:YAG \\
\hline Wavelength & $532 \mathrm{and} / \mathrm{or} 355 \mathrm{~nm}$ \\
\hline Energy per pulse & $800-400 \mathrm{~mJ}$ \\
\hline Pulse repetition rate & $30 \mathrm{~Hz}$ \\
\hline Power & $11-22$ or $24-48 \mathrm{~W}$ \\
\hline beam diameter & $200 \mathrm{~mm}$ (with a $5 \mathrm{x}$ beam expander) \\
\hline beam divergence & $0.1 \mathrm{mrad}$ \\
\hline Emission-reception geometry & Coaxial \\
\hline \multicolumn{2}{|l|}{ Receiver } \\
\hline Type of telescope & Newtonian \\
\hline Diameter, focal length & $1200,3007 \mathrm{~mm}$ \\
\hline Field of view (mrad) & $0.1-2$ \\
\hline Optic fiber & no \\
\hline \multicolumn{2}{|l|}{ Data acquisition } \\
\hline Raman channels N2 (nm) & 387,607 \\
\hline $\mathrm{H}_{2} \mathrm{O}(\mathrm{nm})$ & 407,660 \\
\hline Elastic channels $(\mathrm{nm})$ & 355_a, 355_b, 532_a, 532_b \\
\hline \multirow{2}{*}{ Sounding range $(\mathrm{km})$} & $2-25$ (Raman) \\
\hline & 7-100 (elastic) \\
\hline Time resolution (sec) & 60 \\
\hline Vertical resolution (m) & 15 \\
\hline
\end{tabular}

dry) and wet components at zenith: $\mathrm{ZTD}=\mathrm{ZHD}+\mathrm{ZWD}$, where ZHD refers to zenith hydrostatic delay and ZWD to zenith wet delay. The ZHD is not estimated, but is corrected a priori using the Saastamoinen formula (1972). ZWD is, thus, converted into IWV (Integrated Water Vapor), using simply surface temperature and empirical formulas (Bevis et al., 1992; Emardson and Derks, 1999). The accuracy in GPS, IWV has been assessed by a number of authors, using intercomparisons with radiosondes, microwave radiometers, sun photometers, lidars, and very long interferometry baseline (Foelsche and Kirchengast, 2001; Niell et al., 2001; Bock et al., 2004). The agreement between these techniques is about $1-2 \mathrm{~kg} \mathrm{~m}^{-2}$ for typical values of IWV between 5 and $30 \mathrm{~kg} \mathrm{~m}^{-2}$.

During MALICCA, two types of operational meteorological radiosondes were launched: Vaisala RS92 and Modem M10 radiosondes. For the purpose of this work only RS92 measurements have been used and will be described, while the validation and comparison of M10 performances are the object of on-going studies in the frame of GRUAN (Keckhut et al., 2015).

For the MALICCA-1 campaign, we used a mobile Vaisala model-SPS 220 S/N: Y49101 mobile station, owned by CNRS/INSU and METEO FRANCE. The software used was VAISALA DigiCORA V3.64. The ground check station of radiosonde initialization was a VAISALA GC Set $25 \mathrm{~S} / \mathrm{N}$ :
Z35204. Totex $1200 \mathrm{~g}$ balloons were used for all flight. 15 RS92 GP radiosondes were launched within 2 weeks.

The Vaisala RS92 radiosonde is based on thin-film technology (Salasmaa and Kostamo, 1975) that uses dual HHumicap sensors, which consist of a hydrophilic polymer film acting as dielectric of a capacitor applied on a glass substrate. A reconditioning procedure that alternately heats the two sensors eliminates the problem of sensor icing in clouds. The RS92 response time strongly depends on temperature and on the polymer's ability to adsorb and desorb water vapor. The main measurement uncertainties of RS92 radiosondes, evaluated during several field campaigns (e.g., Miloshevich et al., 2006, 2009; Suortti et al., 2008; Bock et al., 2013), include mean calibration bias, production variability, solar radiation error (daytime only), time-lag error, round-off error and ground-check uncertainty. Miloshevich et al. (2009) provide an empirical correction model for the mean bias error and time-lag error that allow the extension of the relative humidity (RH) measurements with an accuracy of $\pm 4 \%$ up to the lower stratosphere. Recently, the GRUAN data processing for the Vaisala RS92 radiosonde has been developed to meet the criteria for reference measurements (Dirksen et al., 2014). This correction has been applied to the RS92 launched during MALICCA.

\section{Measurement optimization}

One of the objectives of MALICCA campaign has been to optimize the water vapor measurements acquired by the $\mathrm{RMR}-\mathrm{H}_{2} \mathrm{O}$ lidar new system, by improving its over-all efficiency. As discussed in the previous section, to set optimally a lidar system for Raman measurements it is crucial to increase the signal-to-noise ratio (SNR) and to reduce any parasite (spurious) signals that could contaminate the received signals.

The optimization of the lidar system installed at the observatory has been conducted on one hand by testing the different configurations of the system, and on the other hand by evaluating the possible parasite signals.

The campaign lasted 22 nights (from 1-22 April 2013), for a total of approximately $4300 \mathrm{~min}$ of lidar acquisitions, 15 Vaisala RS92 and 12 Modem M10 radiosonde launches. The co-located GPS provided continuous measurements during the whole campaign. Thick mid-level clouds prevented lidar measurements for 6 nights $(3,5,6,12,19,20$ April), while no measurements were performed during the night of 14 April. The lidars operated, on average, 3 to $4 \mathrm{~h}$ per night, with the exception of the $8 \mathrm{~h}$ continuous lidar sessions taken during the nights of 9, 10, 11 (during the new moon) and 22 April.

\subsection{Characterization of the system configurations}

To enhance the SNR, besides the large collecting surface of the telescope, the $\mathrm{RMR}-\mathrm{H}_{2} \mathrm{O}$ lidar can assume several 
Table 3. Lidar performance parameters of the nitrogen Raman channel of the MAIDO- $\mathrm{H}_{2} \mathrm{O}$ lidar for different tested configurations. A temporal integration of $30 \mathrm{~min}$ has been applied to the raw lidar data and no vertical integration. The percentage errors of the linearity correction values (last row) are given in parentheses.

\begin{tabular}{llllll}
\hline $\begin{array}{l}\text { Day } \\
\text { Moon }\end{array}$ & $\begin{array}{l}23 \text { Oct 2012 } \\
\text { Ast qrt }+3 \\
\text { clear sky }\end{array}$ & $\begin{array}{l}\text { 21 Apr 2013 } \\
1 \text { st qrt }+3 \\
\text { clear sky }\end{array}$ & $\begin{array}{l}\text { 21 Apr 2013 } \\
1 \text { st qrt }+3 \\
\text { clear sky }\end{array}$ & $\begin{array}{l}\text { 4 Apr 2013 } \\
\text { 3st qrt }+1 \\
\text { clear sky }\end{array}$ & $\begin{array}{l}\text { 4 Apr 2013 qrt }+1 \\
\text { clear sky }\end{array}$ \\
\hline $\begin{array}{l}\text { Configuration: } \\
\text { Laser }\end{array}$ & $1(532 \mathrm{~nm})$ & $1(355 \mathrm{~nm})$ & $2(355 \mathrm{~nm})$ & $1(355 \mathrm{~nm})$ & $1(355 \mathrm{~nm})$ \\
FOV & $0.55 \mathrm{mrad}$ & $0.55 \mathrm{mrad}$ & $0.55 \mathrm{mrad}$ & $0.55 \mathrm{mrad}$ & $0.69 \mathrm{mrad}$ \\
\hline$z_{\text {err10 }}[\mathrm{km}]$ & 23.3 & 28.9 & 30.4 & 28.3 & 29.1 \\
$z_{\text {err30 }}[\mathrm{km}]$ & 28.1 & 37.5 & 38.5 & 36.7 & 37.3 \\
$B_{N}[$ no of photons $]$ & 17.13 & 0.72 & 1.32 & 0.41 & 0.60 \\
$B_{H}[$ no of photons $]$ & 0.34 & 0.42 & 0.72 & 0.14 & 0.25 \\
$z_{\text {dtb }}[\mathrm{km}]$ & 33.1 & 47.7 & 46.7 & 45.2 & 44.7 \\
$z_{\text {ov }}[\mathrm{km}]$ & 5.5 & 9.0 & 9.2 & 7.4 & 7.1 \\
Linearity correction & $0.07(3 \%)$ & $0.06(3 \%)$ & $0.08(3 \%)$ & $0.10(3 \%)$ & $0.19(3 \%)$ \\
\hline
\end{tabular}

configuration scenarios. As described in Sect. 2, it is possible to double the emitted power by synchronizing the two lasers, to change the wavelength emission from UV to visible and to lower the background noise by reducing the receiver field of view (FOV). Considering that the intensity of the Raman $\mathrm{H}_{2} \mathrm{O}$ channel depends mainly to the highly variable concentration of atmospheric water vapor, the different lidar setups have been evaluated by estimating some representative parameters of the nitrogen Raman channel. In particular for 30 min time-integration lidar sessions, we calculated the maximum altitudes at which the SNR on the nitrogen signal is lower than $0.1,0.3$ ( $z_{\mathrm{err} 10}$ and $z_{\mathrm{err} 30}$, respectively), the signal detectability $\left(\mathrm{dtb}=\left[\left(S_{x}-B_{x}\right) / B_{x}\right]\right)$ is higher or equal to $0.1\left(z_{\mathrm{dtb}}\right)$, the altitude, $z_{\mathrm{ov}}$, of the full overlap between the emitter and the receiver (i.e., the overlap function $\left.f_{z_{\mathrm{ov}}}=1\right)$, the background noise of both Raman channels ( $B_{N}$ and $\left.B_{H}\right)$ and the correction of the signal linearity. Table 3 reports the values of those parameters for each of the tested measurement scenarios during the nighttime lidar acquisition of MALICCA.

\subsubsection{UV and visible emission}

The opportunity of using the emitting wavelength at 355 and $532 \mathrm{~nm}$ (see Sect. 2) allowed a direct comparison of the UV and visible system capabilities that are difficult to determine theoretically. In fact, this estimation depends on several factors such as the Raman backscattering cross-section, laser source availability and power, and the overall detection efficiency.

The lidar sessions acquired with the visible configuration during the first experimental period (September-November 2012) have been compared with the UV lidar sessions of MALICCA. In particular, the first two columns of Table 3 show the results for the visible and UV lidar acquisitions performed with the same system set up (one laser, field of view $=0.55 \mathrm{mrad}$ ) and with, approximately, the same nighttime conditions (clear sky, negligible aerosol load, 3 days after the first moon quarter, the 23 November 2012 and the 21 April 2013, respectively). For the UV emission, in addition to the lowering of the background noise of the nitrogen Raman channel and, consequently, an increment of the detectability, the values of $z_{\operatorname{err} 10}$ and $z_{\operatorname{err} 30}$ increase approximately 5 and $9 \mathrm{~km}$, respectively. These results show that the UV emission (thanks also to the improvements applied to this configuration during MALICCA) seems to be the preferable one. However, to optimize the lidar performance, more tests with both configurations are planned to identify the elements (e.g., optical components, detectors, etc) that contribute to increasing or decreasing the measured signal.

\subsubsection{One and two lasers emission}

The performance of the system can be increased by coupling the two Quanta Ray Nd:YAG laser beams into a unique beam through a system of polarization cubes. Both configurations have been tested and compared during the same night for 2 days (21 and 22 April). The results for 21 April are reported in Table 3. The use of two lasers increases the SNR of 1.5 and $1 \mathrm{~km}$ for $z_{\mathrm{err} 10}$ and $z_{\mathrm{err} 30}$, but a decrease of the detectability, due to the rise of the background noise in both Raman channels, is registered. This phenomenon has been also observed for the night of 22 April with approximately the same rise of background noise from one to two lasers emissions on both channels and further studies are needed to clarify this aspect.

\subsubsection{Field of view}

In the RMR- $\mathrm{H}_{2} \mathrm{O}$ lidar, another way to increase the SNR is to change the FOV of the system through the adjustable aperture of the diaphragm field stop placed at the entrance of the optical units. Modifying the FOV influences the gathering of 
the back-scattering signal and of the background noise, affecting the SNR, the detectability and, in the case of very high-count rates, the linearity response of the PMTs. To find a compromise between these constraints, the effects of several field apertures have been tested during MALICCA. Table 3 reports only the results for the diaphragm aperture of 2 and $2.5 \mathrm{~mm}$ (i.e., a FOV of 0.55 and $0.69 \mathrm{mrad}$, respectively) that optimize the above listed parameters. The two configurations have similar values in terms of SNR and detectability, with the narrower (broader) FOV that optimize the detectability (SNR) of the system and that raises (lowers) the full overlap altitude $\left(z_{\mathrm{ov}}\right)$. This phenomenon is due to the defocusing effect that enlarges the spotlight on the diaphragm aperture decreasing the signal intensity at low range.

\subsubsection{Signal linearity correction}

Another element, which has to be considered for the choice of the FOV and of the emitter set up, is the saturation of PMT that, in case of a too high number of received photons, causes a nonlinear response of the detector. This effect is corrected using the following exponential law (Singh, 1996):

$N_{\mathrm{c}}=N_{\mathrm{r}} \exp \left(-\frac{N_{\mathrm{r}}}{N_{\max }}\right)$,

where $N_{\mathrm{r}}$ are the received photons, $N_{\mathrm{c}}$ the number of counted photons, and $N_{\max }$ the number maximum photons that can be counted by the PMT (system). Due to the coaxial emissionreception geometry, the nitrogen Raman channel of the RMR- $\mathrm{H}_{2} \mathrm{O}$ is subjected to saturation. To evaluate and correct this effect using Eq. (2), the value of $N_{\max }$ for each PMTs of the system has been measured (saturating on purpose the $\mathrm{N}_{2}$ Raman channel) and then a recursive method to resolve the equation has been applied.

The linearity correction (i.e., the ratio $N_{\mathrm{c}} / N_{\mathrm{r}}$ in percentage) for the adopted FOVs are reported in Table 3 as the maximum value of the ratio applied in the nitrogen vertical profile. As expected the saturation effect is higher in case of two-laser emission and with a broader FOV. In conclusion, the FOV of $0.69 \mathrm{mrad}$ will be adopted.

\subsection{Rejection of the residual signals}

Due to the very low $\mathrm{H}_{2} \mathrm{O}$ Raman signal received from the UTLS, a number of known biases must be taken into consideration. To optimize the Raman lidar technique to water vapor measurements, it is necessary to quantify the systematic biases affecting the technique. In particular, several studies (Sherlock et al., 1999; Ferrare et al., 2004; Whiteman et al., 2006; Leblanc et al., 2012) have highlighted that many lidar systems experienced an excess amount of water vapor (wet bias) in the mid-upper troposphere lidar profile, significantly impacting their measurements. The recent work of Whiteman et al. (2012) identified three general causes for this effect: (1) instrumental effects, (2) data processing, (3) atmospheric constituents.
The RMR MAIDO lidar system has been designed to prevent the wet bias effect. During MALICCA, several tests were performed to verify the correct rejection in the water vapor Raman channel system of residual signals due to fluorescence and to Rayleigh, Mie or Raman signal leakage.

\subsubsection{Excess signal due to fluorescence}

As stated by the study of Sherlock et al. (1999a), the weak Raman backscattering signal due to water vapor molecules is susceptible to contamination by fluorescence processes, which can cause systematic errors in Raman Stokes measurements. To reduce this bias, one of the technical solutions adopted for the RMR MAIDO has been to avoid the using of an optical fiber to transfer the backscattered signals to the optical ensemble. This element has been proved to be one major source of fluorescence, causing a contamination signal on the water vapor Raman channel.

However fluorescence processes could arise in any optical component of the lidar system. Thus, to verify the possible presence of such contamination, during the night of 4 April, the interference filter on the water vapor channel has been replaced by one $10 \mathrm{~nm}$ band-pass cavity interference filter centered at $432 \mathrm{~nm}$. Since a significant backscatter contribution from atmospheric constituents is not present in this spectral region, any observed signal may be due to the fluorescence.

On the acquired profile (not shown) and after an integration time of 3-4h, one can detect on the background noise, the presence of a weak exponentially decreasing signal in the first $5-6 \mathrm{~km}$. The effect could be attributed to the fluorescent re-emission of the lidar receiving optics that are excited by the high elastic backscattering signal coming from low altitudes. This signal corresponds to a contribution of less than $0.5 \mathrm{ppmv}$ in terms of water vapor mixing ratio. Above this region, the received signal is not distinguishable from the sky background noise. In presence of clouds, the effect may increase by one or two magnitudes, however in the midtroposphere, it will remain 2 orders of magnitude smaller that the water vapor signal. These tests allow concluding that the bias due to florescence of components (if any) is negligible.

\subsubsection{Excess signal due to Rayleigh, Mie or Raman signal leakage}

A signal contamination similar to fluorescence, which can affect the measurement of upper tropospheric and lower stratospheric water vapor, can also be originated by an insufficient optical density (OD) in the water vapor filter at the wavelength of the Rayleigh, particle (at $355 \mathrm{~nm}$ ) or Raman nitrogen return $(387 \mathrm{~nm})$. The optical elements of a lidar system must consequently satisfy very strict requirements on the rejections of other wavelengths.

In the RMR MAIDO lidar, the optical boxes (see Sect. 2 and Fig. 1) have been designed considering that, to limit the contamination due to the Rayleigh, Mie or Raman nitrogen 


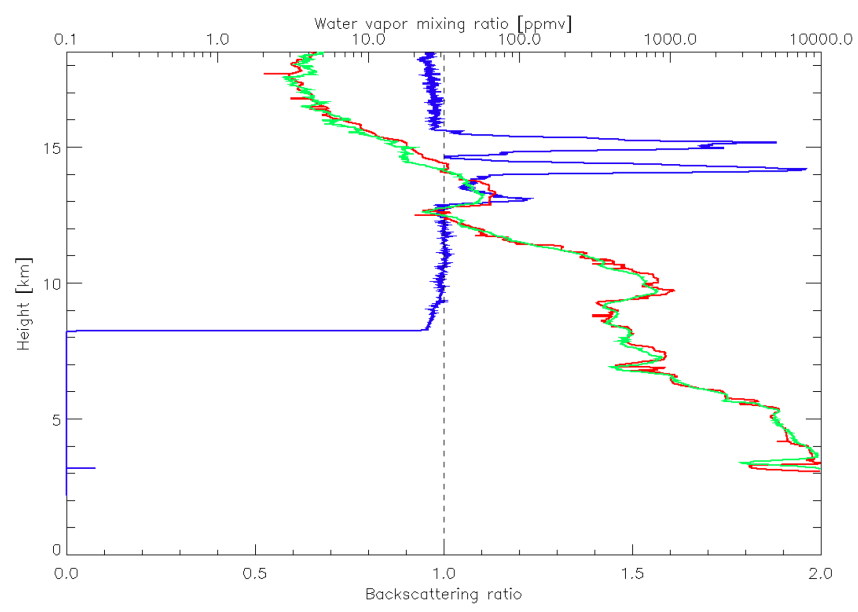

Figure 2. Backscattering ratio (i. e. the ratio between the Rayleigh and the Raman channels at 355 and $387 \mathrm{~nm}$, respectively) and WVMR profiles (blue and green curves, respectively) observed during the night of 8 April 2013, together with the WVMR measured by the co-located RS92 radiosonde (red curve). Both lidar profiles are integrated for $60 \mathrm{~min}$ starting at the radiosonde launching time (i.e., 20:50 UT).

signal, the OD required in the Raman water vapor channel is approximately $10 / 11,13 / 14$ and 7 , respectively. Thus, the series of two high pass and one band pass filters (HP-IFF1 and HP-IFF2 and BP-IFF2 in the Fig. 1), successively placed before the $\mathrm{H}_{2} \mathrm{O}$ PMT, guarantee a nominal OD of 15 and of 9 at $355 \mathrm{~nm}$ and at $387 \mathrm{~nm}$, respectively.

To test the system rejection (to Mie signal intrusion), let us consider Fig. 2, related to the lidar measurements of 8 April: the backscattering ratio profile (blue line), derived as the ratio between the Rayleigh low temperature and the Raman nitrogen channels, is depicted together with the water vapor mixing ratio profiles measured by the lidar and the colocated RS92 radiosonde (green and red lines, respectively). Both lidar profiles are integrated for $60 \mathrm{~min}$ starting at the radiosonde launching time (i.e., 20:50 UT). In the presence of cloud, as the multi-layer thin cirrus observed in Fig. 2 between 12.8 and $15.5 \mathrm{~km}$, there may be a contribution due to the Mie scattering. The comparison of water vapor profiles derived from lidar and radiosonde at the cirrus altitude range highlights that, for this case, there is no evidence of signal contamination in the water vapor Raman channel. In particular, if present, the magnitude of the contamination is included in the lidar statistical error, which is, for this case, approximately 5 and 2 ppmv at the cloud top and at the cloud bottom, respectively. The water vapor lidar profile has been calibrated through the radiosonde profile method (see Sect. 4).

\subsection{Performance characterizations}

The performance of the system has been analyzed in terms of the relative error, namely the ratio between the lidar statisti- cal error and the non-calibrated WVMR (dw and $w$, respectively). Assuming Poisson statistics, the ratio is given following Whiteman et al. (2006):

$$
\frac{\mathrm{d} w}{w}=\frac{\sqrt{S_{N}^{2} \times\left(N_{H}+\sigma_{B H}^{2}\right)+S_{H}^{2} \times\left(N_{N}+\sigma_{B N}^{2}\right)}}{S_{N} S_{H}},
$$

where $\sigma_{B x}$ are the background error for each Raman channel, while the $S_{x}$ and $N_{x}$ have the same meaning of the Eq. (1) in Sect. 2.1.

The expected performances of the MAIDO- $\mathrm{H}_{2} \mathrm{O}$ system were evaluated by Hoareau et al. (2012) through a numerical simulation of the lidar signals, which used as reference the nominal values of the total lidar receiver optical efficiency $\left(\xi_{x}\right.$ in the Eq. 1) and the water vapor mixing ratio profiles from ECMWF ERA-40 reanalysis.

The results of this simulation have been compared to a sample of 10 nighttime measurements acquired during MALICCA, which have a similar configuration to that foreseen by the simulation (i.e., one laser emission, $\mathrm{FOV}=0.55 \mathrm{mrad}$ ). The mean, maximum and minimum values of $B_{H}$ and of the altitudes within a relative error of 15 and $30 \%$ for $\mathrm{H}_{2} \mathrm{O}$ measurements $\left(z_{15 \%}\right.$ and $\left.z_{30 \%}\right)$ are listed in Table 3 together with the expected values. These values have been obtained with a fixed temporal and vertical signal integration of $30 \mathrm{~min}$ and $150 \mathrm{~m}$, respectively.

Despite the narrower FOV and the higher sky background noise ( 0.25 vs. $0.55 \mathrm{mrad}$ and 4.8 vs. 0.7 photons between the simulation and the real values), the simulation seems to have overestimated the performance of the MAIDO- $\mathrm{H}_{2} \mathrm{O}$ lidar. In fact, even considering the maximum values of the sample, the difference in height between the expected and measured $z 15 \%$ and $z 30 \%$ is 1.6 and $2 \mathrm{~km}$, respectively. This result can be explained both by the fact that the reference water vapor profile is not appropriate to describe the atmospheric water content observed during the short time period of MALICCA campaign and by the likely discrepancy between the value of $\xi_{x}$ derived by the specifics of each optical components and its real value.

As already discussed, the main problem of the water vapor Raman measurement is the low intensity of the signal in comparison to the associated statistical error, which is dominant in the Raman lidar technique. To reduce this error, the raw data has to be integrated in time and space with the consequent loss of vertical and temporal resolutions. To optimize the compromise between accuracy and resolution, a height-dependent smoothing scheme has been implemented. In this first data treatment a simple moving average has been adopted as a smoothing filter. The mean is taken from an equal number of sampling bins $\left(N_{\mathrm{b}}\right)$ on either side of a central bin. The value of $N_{\mathrm{b}}$ is automatically computed as a function of height so that, below $13 \mathrm{~km}$, the statistical error is always less than $10 \%$. The resulting WVMR relative error profile, depicted in Fig. 3 as the mean profile for the lidar measurements considered in Table 4, has been calcu- 
Table 4. Comparison of the MAIDO- $\mathrm{H}_{2} \mathrm{O}$ capabilities estimated by the numerical simulation of Hoareau et al. (2012) and calculated as the mean of ten nighttime measurements acquired during MALICCA. The minimum and the maximum values (in the brackets) of the measured parameters are also reported.

\begin{tabular}{lll}
\hline & $\begin{array}{l}\mathrm{H}_{2} \mathrm{O} \\
\text { Simulation }\end{array}$ & $\begin{array}{l}\mathrm{H}_{2} \mathrm{O} \\
\text { MALICCA (10 session) }\end{array}$ \\
\hline Lidar & $1(355 \mathrm{~nm})$ & $1(355 \mathrm{~nm})$ \\
configuration & $0.25 \mathrm{mrad}$ & $0.55 \mathrm{mrad}$ \\
Data integration & $30 \mathrm{~min}-150 \mathrm{~m}$ & $30 \mathrm{~min}-150 \mathrm{~m}$ \\
\hline$B_{H}[$ no of pht] & 4.8 & $0.7(0.5-1.8)$ \\
$z_{\mathrm{H}_{2} \mathrm{O} 15 \%[\mathrm{~km}]}$ & 14.6 & $12.3(9.7-13.0)$ \\
$z_{\mathrm{H}_{2} \mathrm{O} 30 \%[\mathrm{~km}]}$ & 16.3 & $13.4(11.0-14.3)$ \\
\hline
\end{tabular}

lated for a temporal integration of 30 and 120 min (black and red thick curves, respectively). The total number of bins $\left(2 N_{\mathrm{b}}+1\right)$, which is the vertical resolution $(\mathrm{d} z)$ of the water vapor profile, is also represented as a step black curve.

The developed procedure maintains a high vertical resolution in the lower and the middle troposphere $(\mathrm{d} z$ ranges from 0.015 to $0.045 \mathrm{~km}$ between 2 and $8 \mathrm{~km}$ ). In the upper troposphere (above $13 \mathrm{~km}$ ), looking at the 120 min integrated profile of Fig. 3, the vertical resolution gradually degrades with random errors that increase to $30 \%$, more than 50 and $100 \%$ around 15,16 and $17 \mathrm{~km}$, respectively. To lower further the statistical error in the UTLS region, lidar data have to be integrated over one or more nighttime sessions (see Sect. 5).

\section{Calibration}

\subsection{Long-term calibration strategy}

Considering that molecular extinction can be derived by models, climatological data or measurements (as well as the density of the atmospheric absorbers), in first approximation, the Eq. (1) of the WVMR measured by the RMR- $\mathrm{H}_{2} \mathrm{O}$ MAIDO Lidar can be expressed in a simplified form:

$\operatorname{WVMR}(z)=C \times \frac{\xi_{N}}{\xi_{H}} \frac{\mathrm{d} \sigma_{N} / \mathrm{d} \Omega}{\mathrm{d} \sigma_{H} / \mathrm{d} \Omega} \times \frac{S_{H}(z)-B_{H}}{S_{N}(z)-B_{N}} \times \Gamma_{\Delta}^{\mathrm{a}}$,

where $C$ is the calibration coefficient of the measurements, namely the factor that converts the measured profiles of backscattered radiation into a useful geophysical variable (i.e., mixing ratio), while $\Gamma_{\Delta}^{\mathrm{a}}$ is the particulate differential extinction term for the Raman wavelengths of nitrogen and water vapor.

The estimation of the calibration coefficient represents a well-known issue that can still limit a systematic and operational employment of this technique. For this reason, during the last 2 decades, several efforts have been made to develop a methodology relatively simple, repeatable, stable, and that can be fully characterized in terms of accuracy and asso-

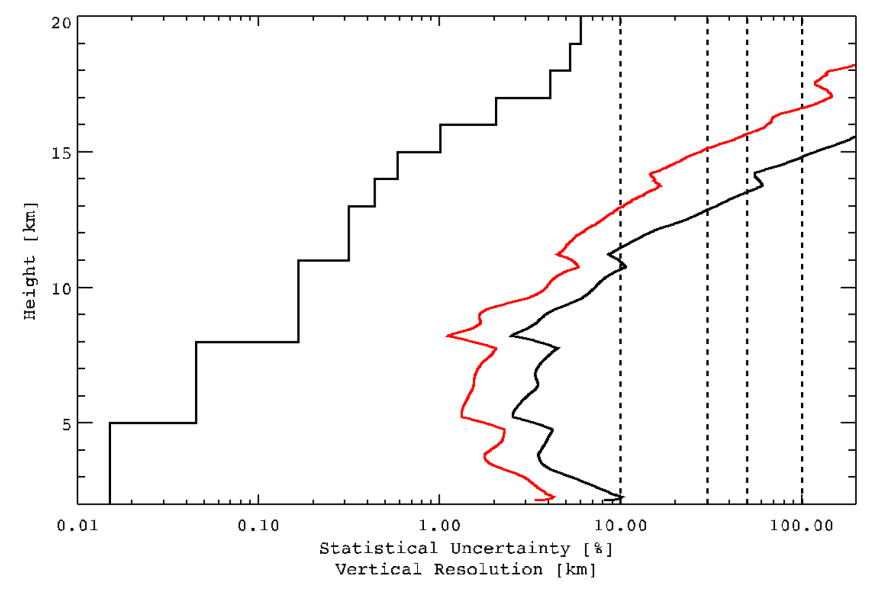

Figure 3. Mean statistical uncertainty (\%) after the vertical filtering scheme calculated for 10 nighttime measurements with the same lidar configuration. Data are temporally integrated for 30 and $120 \mathrm{~min}$ (black and red curves, respectively). The step black curve represents the corresponding vertical resolution $(\mathrm{km})$.

ciated uncertainties (Ferrare et al., 1995; Whiteman et al., 2003). In the frame of the NDACC, these requirements are fundamental in order to ensure the proper long-term monitoring of the (UTLS) water vapor mixing ratio.

Two main approaches exist: the internal calibration, which consists of calculating every single term composing $\mathrm{C}$, and the external calibration, which consists of deducing $\mathrm{C}$ by comparison with the WVMR measured through another sensor. The former method is limited by the measure of the ratio of the Raman differential backscattering cross section at the two wavelengths, which is affected by an uncertainty of $10 \%$ (Penney and Lapp, 1976). The accuracy of the latter method depends on the external sensors' accuracy and on the differences in time and volume sampling between the employed instruments.

To reduce as much as possible the uncertainties arising from these approaches, an hybrid method, which couples both strategies, has been recently implemented (Leblanc and McDermid, 2011): the receiver transmittance of each lidar session is systematically monitored and an absolute calibration, derived by comparison through another instrument, is applied to all lidar acquisitions whose system response has not significantly changed. In other words, in a first step, instrumental stationary periods (ISPs, no major changes in receiver response) are detected through system monitoring and, in the second step, a single calibration value is calculated for all the measurements owing to the same ISP. This method, recently discussed at a NDACC workshop (Greenbelt, Maryland, May 2010), has been recommended as a standard procedure for all the NDACC water vapor Raman lidars.

The RMR $-\mathrm{H}_{2} \mathrm{O}$ lidar is also designed to utilize a hybrid calibration strategy and one of the aims of MALICCA was 


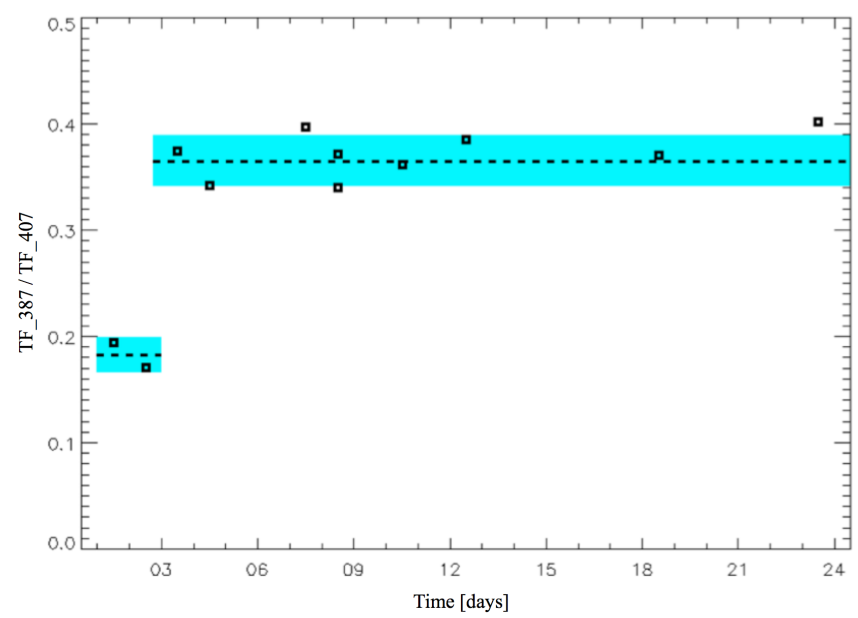

Figure 4. Temporal evolution of the transmittance functions of the two Raman channels measured through the lamp method during the MALICCA campaign. Dashed horizontal lines represent the median values, while the blue light region defines the residual variability (mean \pm standard deviation).

to set up and validate a procedure that guarantees repeatable and stable calibration coefficients.

\subsection{System monitoring: calibration lamp and passive daytime observation}

The first step is monitoring the system by measuring the receiver transmittance to ensure that no instrumental changes occurred between two different lidar sessions.

In particular, for the MAIDO RMR- $\mathrm{H}_{2} \mathrm{O}$ lidar two methods are used: the calibration lamp (CL), and the passive daytime observations (PDOs). As highlighted by the works of Leblanc and McDermid (2008) and of Whiteman et al. (2011a) for CL and by the work of Hoareau et al. (2009) for PDOs, these methods cannot be used to provide an accurate quantification of the system optical efficiency, but only to identify ISPs.

Both the methods are based on collecting the ratio of the collected signals in the water vapor and the nitrogen channels that represents the ratio of the transmittance functions of the two Raman channels $\left(\mathrm{TF}_{387} / \mathrm{TF}_{407}\right)$. Previous work shows that even if the lamp emission can vary with time the ratio will remain the same.

An ORIEL model 6251NS $75 \mathrm{~W}$ Xenon lamp has been mounted on a movable support that, for each measurement, is shifted across the top of the primary telescope and directly illuminates its surface. The CL monitoring procedure consists of acquiring the signals coming exclusively from the illumination by the lamp and then deriving $\mathrm{TF}_{387} / \mathrm{TF}_{407}$. This procedure, which lasts 10 min before the beginning of each water vapor lidar acquisition, has been tested for 11 lidar sessions between 1 and 24 April.
The time series of $\mathrm{TF}_{387} / \mathrm{TF}_{407}$, calculated as the mean of 1-min ratios, are shown in Fig. 4. Because of high background noise registered in the nitrogen Raman channel during the first days of MALICCA, on 3 April we replaced the PMT on this channel. This instrumental change is well detected by the doubling of the $\mathrm{TF}_{387} / \mathrm{TF}_{407}$ mean (horizontal black dashed line) calculated for the lidar session before and after 3 April, respectively. A residual variability (mean \pm standard deviation, blue light regions in the plot) of approximately 9 and $7 \%$ characterizes the two identified periods. This is due to the fact that the optical arrangement of the lamp allows lighting only a portion of the telescope surface, causing a nonuniform illumination of all of the receiver components. Furthermore, this arrangement has been subjected to small variations. The right side of Fig. 5 depicts the partial illumination of the mirror by the optical arrangement of the CL, while the left side schematically represents the effect on the $R_{\mathrm{tf}}$ values caused by illuminating four different parts of the RMR-H2O telescope surface. A similar range of values (7\%) was obtained by Whiteman et al. (2008) using a calibration lamp scanned over the full aperture of the Howard University Raman lidar.

A light trend of approximately $1-2 \%$ is also recorded during each CL session, probably due to insufficient heating (warm up) of the lamp.

Passive daytime observations to identify ISPs were also tested during MALICCA. The technique consists of measuring the daytime sky background radiation at a given time, changing with season to keep the same solar zenith angle, on the two Raman channels. The main limitation of the method is that clear-sky conditions must be fixed for every measurement, because the effect of aerosol and clouds has a strong impact on the $\mathrm{TF}_{387} / \mathrm{TF}_{407}$ retrieved values. This requirement limits the employment of the technique. In fact, contrary to the nighttime, the observatory, during daytime, is characterized by a predominance of cloudy conditions. This fact is pointed out by the Fig. 6, where the PDOs performed on 2 and 5 April are depicted in the left and the right plot, respectively. The measurements, both starting at 8:20 UTC (corresponding to a zenith angle of approximately $63^{\circ}$ ), last $30 \mathrm{~min}$. The PMT change is still noticeable (the mean $\mathrm{TF}_{387} / \mathrm{TF}_{407}$ value is 0.55 and 1.6 approximately for 2 and 5 April, respectively), but the $\mathrm{TF}_{387} / \mathrm{TF}_{407}$ of 5 April are strongly affected by a rapid transit of several small clouds (a typical condition at Maïdo site during daytime convection), causing a variation of $\mathrm{TF}_{387} / \mathrm{TF}_{407}$ values up to $20 \%$. Furthermore, the hypothesis that the system behaves similarly during nighttime and daytime has to be verified.

Given these results, major instrumental changes (i.e., variations of $\mathrm{TF}_{387} / \mathrm{TF}_{407}$ greater than $10-15 \%$ ) of the RMR$\mathrm{H}_{2} \mathrm{O}$ lidar system will be monitored through the implementation of CL method. However, to gain on lamp stability and ameliorate the method sensitivity, it is planned to wait $10 \mathrm{~min}$ before starting such a measurement and to fix the lamp position to suppress any variation. 

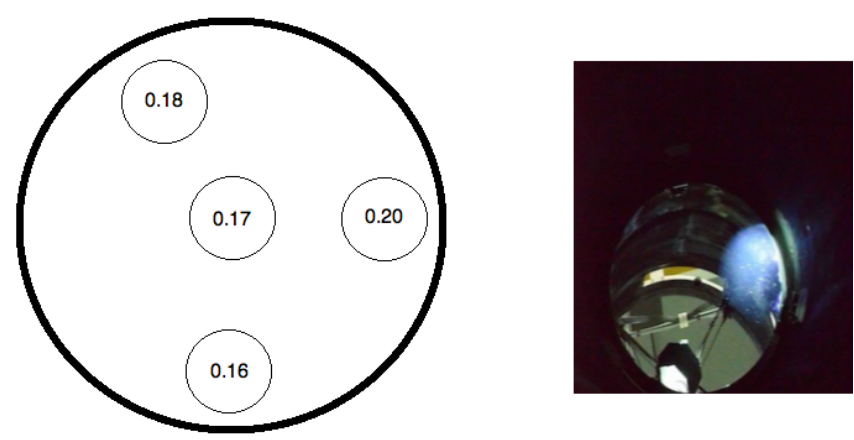

Figure 5. Left: representation scheme of the $R_{\mathrm{tf}}$ values in functions of the illuminated portions of the RMR- $\mathrm{H}_{2} \mathrm{O}$ telescope surface. Right: example of the partial illumination of the mirror by the optical arrangement of the calibration lamp.

\subsection{Total column calibration}

Once the ISP's are identified, a calibration value should be calculated. To derive this value, several sensors have been adopted and evaluated in the literature. In particular the most common method is using co-located radiosonde profiles because of their wide availability, better accuracy in the results compared to other sounding techniques, and a relatively wide vertical range of valid measurements. However, though no changes are performed on the lidar system, the natural variability of tropospheric water vapor can lead to calibration changes of $15 \%$ or larger from night to night (Leblanc et al., 2012). In fact the radiosonde, during its ascension, samples different regions of the atmosphere regarding the lidar. Repeating the calibration through several radiosonde launches during a single lidar session can resolve the problem, but it is not affordable in the frame of long-term routine measurements due to a sensible increase of the costs.

Another solution is comparing the integrated water vapor (IWV) column retrieved by the lidar and a co-located instrument such as the GPS. This type of calibration considerably reduces the costs and, potentially, has the advantage of being more stable over longer periods of time, because it is not subject to manufacturer changes (e.g., Vaisala radiosonde versions). The DEMEVAP campaign (Bock et al., 2013) has revealed an uncertainty of several per-cent, and comparisons of the IWV by different methods show differences of 5-10\%. The main drawbacks are the difficulty of establishing the absolute accuracy of GPS IWV and the usual biaxial configuration of lidar systems that does not permit to sense the lowermost layer of the atmosphere, which contains the main fraction of water vapor. Thus, the extension of the lidar water vapor profile downward to the ground (e.g., linear interpolation with surface measurements) could add a non-negligible uncertainty or bias.

In the case of the $\mathrm{RMR}-\mathrm{H}_{2} \mathrm{O}$ lidar, its emitter-receiver coaxial geometry reduces the latter problem, permitting to have the first available point of the water vapor lidar profile
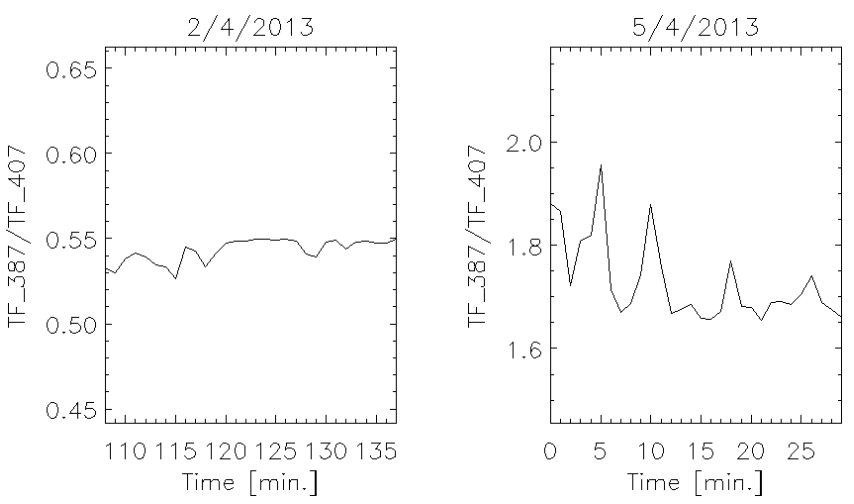

Figure 6. $\mathrm{TF}_{387} / \mathrm{TF}_{407}$ determined by $30 \mathrm{~min}$ of passive daytime observations at approximately $63^{\circ}$ of the solar zenith angles for 2 and 5 April (left and right plot, respectively).

Table 5. Principal results (median, pseudo-SD, standard error values and the number of points) for the three calibration methods tested during MALICCA.

\begin{tabular}{lcccc}
\hline & $C_{\text {med }}$ & $\begin{array}{c}\text { PSTD } / C_{\text {med }} \\
(\%)\end{array}$ & $\begin{array}{c}\mathrm{Se} / C_{\text {med }} \\
(\%)\end{array}$ & \# points \\
\hline Lid-GPS IWV & 214 & 13 & 2 & 55 \\
Lid-RDS prof & 221 & 9 & 3 & 11 \\
Lid-RDS IWV & 220 & 7 & 2 & 11 \\
\hline
\end{tabular}

only $15 \mathrm{~m}$ above the station. The co-located GPS, described in Sect. 2.3, can provide a reference value of IWV every hour. For these reasons a calibration strategy based on GPS IWV was tested during MALICCA.

The RMR- $\mathrm{H}_{2} \mathrm{O}$ IWV is calculated using the lidar water vapor profile completed adding a surface point derived by the humidity measurement of the co-located COMET T7310 automatic weather station and an upward extension (above $16 \mathrm{~km}$ ) based on the European Center for Medium-Range Weather Forecast (ECMWF) operational water vapor profiles. The ECMWF data, re-sampled on a latitude-longitude resolution grid of $1.125^{\circ}$ and converted to water vapor mixing ratio by means of the empirical saturation vapor pressure over liquid water formulas of Hyland and Wexler (1983). It must be noted that the ground point can affect the RMR- $\mathrm{H}_{2} \mathrm{O}$ IWV value even for $1 \%$, while the ECMWF data has an impact of less than $0.1 \%$.

The calibration procedure consists of integrating only the lidar profiles acquired $30 \mathrm{~min}$ before and after the hourly IWV values retrieved by the GPS, calculating the corresponding un-calibrated $\mathrm{RMR}-\mathrm{H}_{2} \mathrm{O}$ IWV value and scaling it to the IWV GPS coincident value.

The time-series of the IWV GPS calibration coefficients associated to their errors (black vertical bars) are displayed in Fig. 7 for the period 1-24 April. The horizontal black dashed lines depict the median calibration factors for the two ISPs identified by the calibration lamp. The $\mathrm{N}_{2}$ PMT substitution 


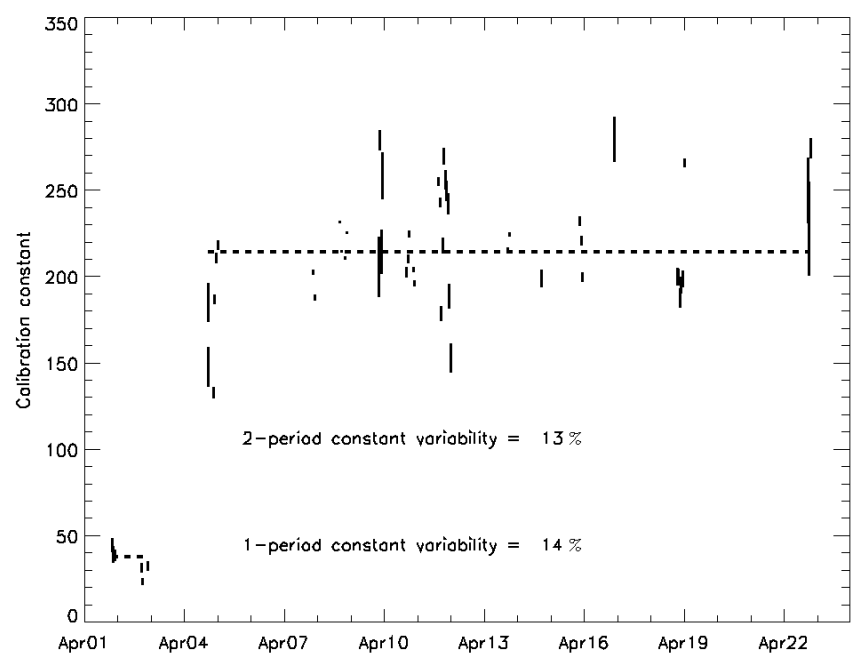

Figure 7. Time series of lidar calibration factors with their associated errors for the RMR- $\mathrm{H}_{2} \mathrm{O}$ lidar determined by IWV GPS during the MALICCA campaign. Dashed horizontal lines indicate the median values for the ISPs identified by the CL monitoring method.

on 3 April causes a jump of the calibration median coefficient by a factor of more than 5 , with a variability (i.e., the normalized pseudo-standard deviation) of approximately 13-14\% for the two periods. To validate the procedure, the calibration coefficients have been also estimated through 11 of the 15 RS92 launched during the campaign. In particular two methods were performed: radiosonde-lidar comparison of water vapor profiles and of water vapor columns (PROF RS92 and IWV RS92, respectively). For the former, the raw lidar signals are integrated for 60 min starting at the radiosonde lauching time $\left(t=t_{0}\right)$. The calibration coefficient is computed through the median of the ratio of all radiosonde-lidar matching pairs, in the altitude range between 3 and $11 \mathrm{~km}$. The upper limit is fixed to keep the lidar SNR higher than 10, while the lower is fixed to exclude the lowest points of the lidar profile that could be affected by a different response of the two Raman channels at low ranges (see Sect. 5.1). The latter method estimates the calibration factor from the IWV calculated by the RS92, using the same data set of the former. The RS92 water vapor profiles have been corrected following the Dirksen et al. (2014) criteria for reference measurements, in the frame of GRUAN data processing.

In the Fig. 8, the calibration coefficients derived from the three methods are depicted with different symbols and colors (black crosses, red diamonds and green squares for IWV GPS, IWV RS92 and PROF RS92, respectively) for the period 8-16 April. The Table 5 resumes the principal results in terms of the median calibration constant $\left(C_{\text {med }}\right)$, pseudostandard deviation (PSTD) and standard error (SE, the sample's standard deviation divided by the square root of the sample size).

The difference of approximately $2-3 \%$, obtained comparing $C_{\text {med }}$ derived by IWV GPS and by IWV RS92, could be due to the mean bias of $-0.5 \mathrm{~kg} \mathrm{~m}^{-2}$ that has been observed, during MALICCA, between the instruments.

Another difference between GPS and RS92 calibration methods is the high variability that characterizes the GPS strategy compared to the RS92 procedures that have a variability (7 and $9 \%$ for IWV RS92 and PROF RS92, respectively). These values are consistent to those obtained with other instruments (Whiteman et al., 2007; Hoareau et al., 2009; Dionisi et al., 2010; Leblanc et al., 2012). This variability clearly emerges for the $8 \mathrm{~h}$ lidar session between the 15:00 UTC on the 11 April and the 00:00 UTC on 12 April (highlighted by the black vertical dotted lines in the plot) where the calibration factor varies from almost 270 to 150 .

The Fig. 9 shows the time series of IWV measured by GPS, RS92 and the RMR- $\mathrm{H}_{2} \mathrm{O}$ lidar calibrated through the GPS procedure. The comparison shows an overall quite good agreement with a IWV cycle lasting 2 days. Nevertheless if we consider the 11 April, it can be noticed the rapid drop of more than $50 \%$ of the IWV GPS values, and the corresponding decrease measured by the lidar is of approximately $35 \%$. In the last part of the night, a small increase of IWV is observed by the lidar and the RS92 and not by the GPS. These dissimilarities can be explained by the fact that the instruments, although co-located, do not measure the same volume of the atmosphere: GPS integrates fields of view over nearly all the hemisphere, RS92 is measuring over the path of the balloon, Lidar samples a vertical profile above the station. The spatio-temporal variability of IWV can highly affect intercomparison experiments between instruments that have a temporal matching longer than $10 \mathrm{~min}$ and a spatial matching greater than $100 \mathrm{~m}$ (Vogelmann et al., 2011). This sampling difference is probably stressed by the position of Réunion island that, being on the border of the Inter Tropical Convergence Zone (ITCZ), can assume different water vapor regimes locally varying that depend on the meteorological situation. Furthermore, the role of the mountain-related circulation should be also taken into account.

The comparison through the $S_{\mathrm{e}}$ of the three samples highlights that the methods have a comparable standard deviation of the sample mean. Thus, the high variability of IWV GPS strategy is balanced by the possibility of having a greater number of calibration coefficients during a lidar acquisition session.

Given these considerations, further tests will be performed to determine and reduce the factors increasing the variability with the aim of optimizing the IWV GPS procedure so that it could be used as the standard calibration methodology for RMR- $\mathrm{H}_{2} \mathrm{O}$ lidar. The estimated calibration coefficient will be then compared daily and validated through radiosonde data derived by the meteorological station located $20 \mathrm{~km}$ from the station as well as to the other sensors in case of intensive measurement campaigns. 


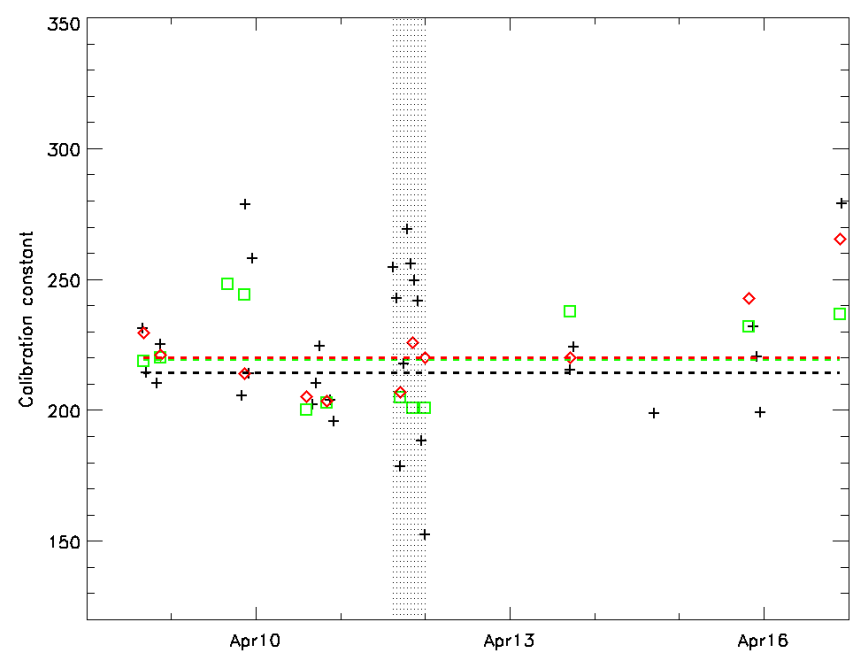

Figure 8. Time series of the lidar calibration factors for the RMRH2O lidar determined by IWV GPS, IWV RS92 and PROF RS92 approaches (black crosses, red diamonds and green squares, respectively) for the period 8-16 April. Dashed horizontal lines indicate the median values for each method. Dotted vertical lines highlight the lidar measurement session acquired between 15:00 UTC of the 11 April and the 00:00 UTC of 12 April 2013.

\section{Lidar capabilities}

\subsection{RS92 radiosondes-lidar comparisons}

A total of 15 RS92 radiosondes were launched over the duration of MALICCA. In Fig. 10 two examples of the water vapor profiles measured by Maïdo $\mathrm{H}_{2} \mathrm{O}$ lidar and the corrected RS92 radiosonde during the nighttime lidar sessions of 9 April and 10 April (left and right plot, respectively) are depicted. The lidar profiles are obtained from a $1 \mathrm{~h}$ integration starting at the corresponding balloon launch time and vertically integrated following the smoothing scheme discussed in Sect. 3.3. Both sessions highlight in the middle troposphere an excellent agreement between the two instruments, which detect the same fine vertical structures of water vapor up to $10 \mathrm{~km}$. In the upper troposphere a good concordance is kept up to $16 \mathrm{~km}$ for the night of 9 April while, for 10 April, at the altitudes between $11-15 \mathrm{~km}$, the lidar measures a moister layer in the upper troposphere of approximately $0-40 \%$ more than the RS92. This difference will be discussed afterwards, however it has to be considered that, at these altitudes, the lidar statistical relative error rapidly increases from $10-50 \%$. It is also noteworthy that all the lidar water vapor profiles presented here have been calibrated using the coefficient derived from the prof-RS92 calibration method (see Sect. 4.3), which is characterized by a lower variability.

The lidar data within $1 \mathrm{~h}$ of balloon launch have been systematically processed and compared with the simultaneous co-located RS92 corrected measurements. Fig. 11 shows the mean WVMR relative difference (i.e., (lidar-RDS)/RDS,

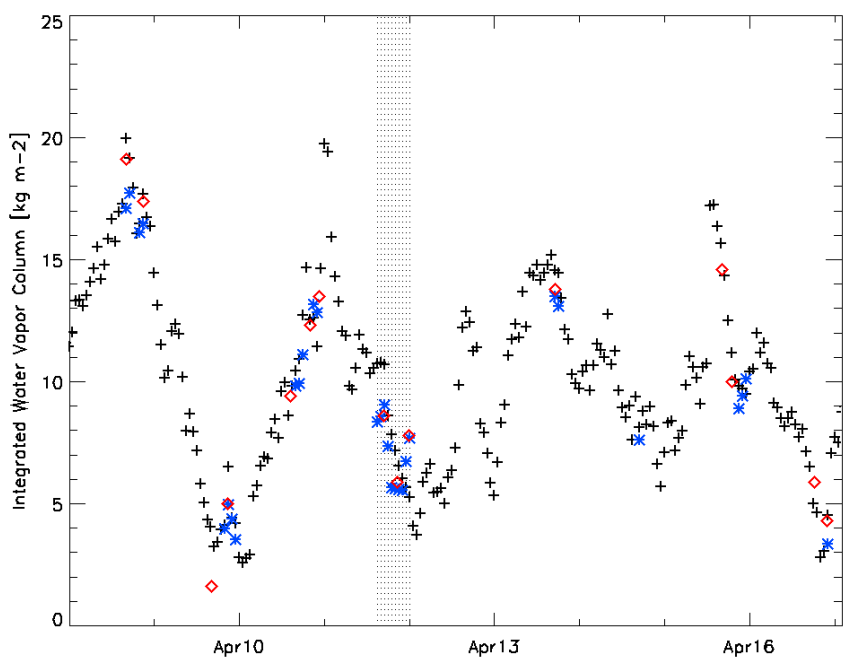

Figure 9. Time series of IWV estimated by GPS, RS92 and RMR$\mathrm{H}_{2} \mathrm{O}$ lidar calibrated through the GPS procedure (black crosses, red diamonds and blue stars, respectively) for the period 8-16 April. Dotted vertical lines highlight the period between 15:00 UTC of the 11 April and the 00:00 UT of 12 April 2013.

green dashed curve) between 12 RS92 flights and the 12 corresponding $1 \mathrm{~h}$ integrated lidar profiles. The mean lidar statistical error of these sessions (red curves), which attains more than $30 \%$ at $14 \mathrm{~km}$, prevented to extend the lidar profiles above this altitude. To compare better the measurements, the profile of the relative difference averaged on 1-km thick layer has also been plotted together with the related standard deviations (black squares and horizontal black bars, respectively). In the first atmospheric layer (2-3 km), a negative bias of approximately $10 \%$ is observed. A possible explanation is a partial (or different) illumination of the photocathode surfaces that could have produced a different instrumental response of the two Raman channels at low ranges. Further comparisons are needed to clarify this aspect. A positive bias $(7-8 \%)$ is present between 3 and $6 \mathrm{~km}$, while a negligible difference characterizes the vertical layer $6-10 \mathrm{~km}$. The figure confirms the good agreement in middle troposphere up to $10 \mathrm{~km}$, where the relative mean difference, in absolute, is below $10 \%$. The upper troposphere above $10 \mathrm{~km}$, is, on the contrary characterized by a rise of the mean relative difference with values up to $20 \%$ between 11 and $13 \mathrm{~km}$. However, this difference seems to be mainly caused by the measurements acquired during the nights of 10 and 11 April. In fact, excluding the five lidar-RS92 comparisons taken during those nights (blue squares in Fig. 11), the positive bias between lidar and RS92 considerably lowers, remaining below $10 \%$. Therefore, this disagreement, depicted for the night of 10 April by the Fig. 10, can be attributed to the difference in the water vapor amount sensed above the Maïdo station by the lidar and the one sampled by the radiosonde. In fact, in 

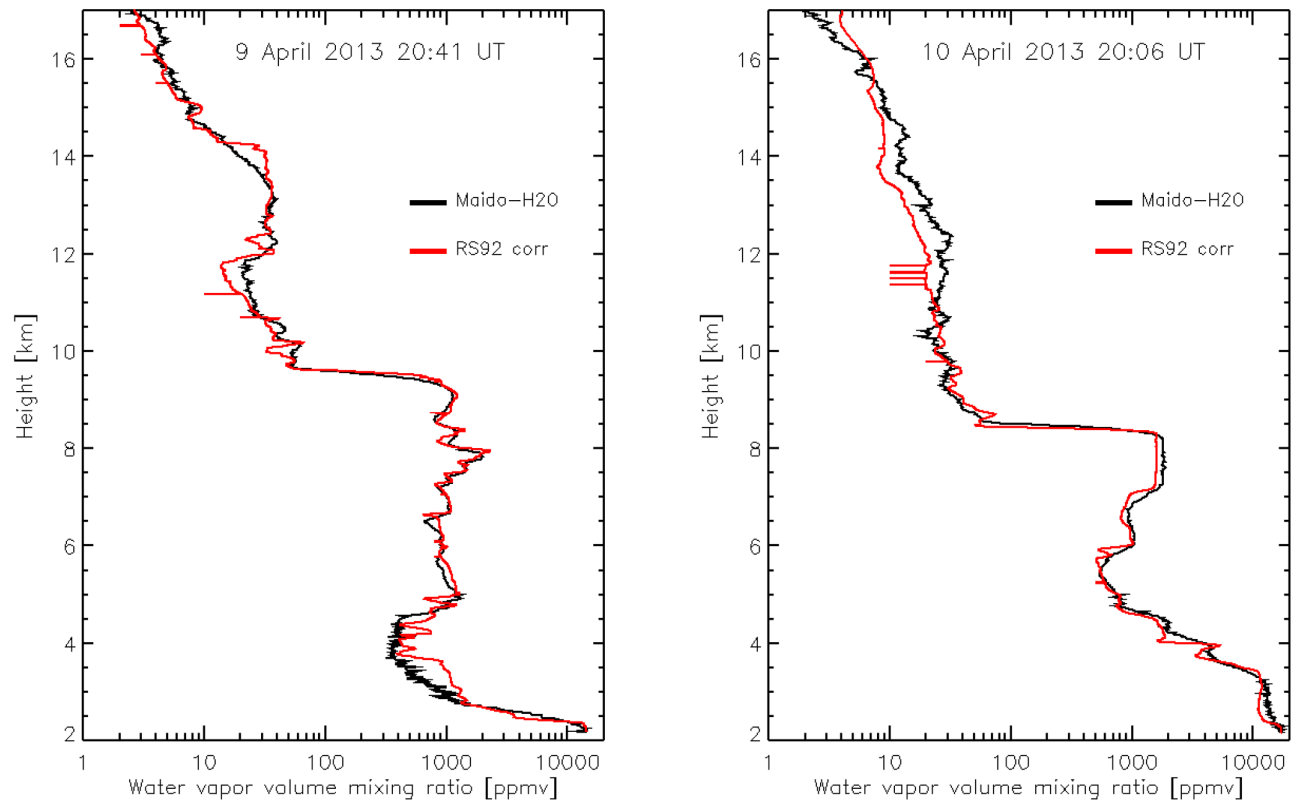

Figure 10. Example of two water vapor mixing ratio profiles measured simultaneously by the Maïdo lidar and the RS92 radiosondes (black and red curve, respectively) during the nighttime measurement sessions of 9 and 10 April.

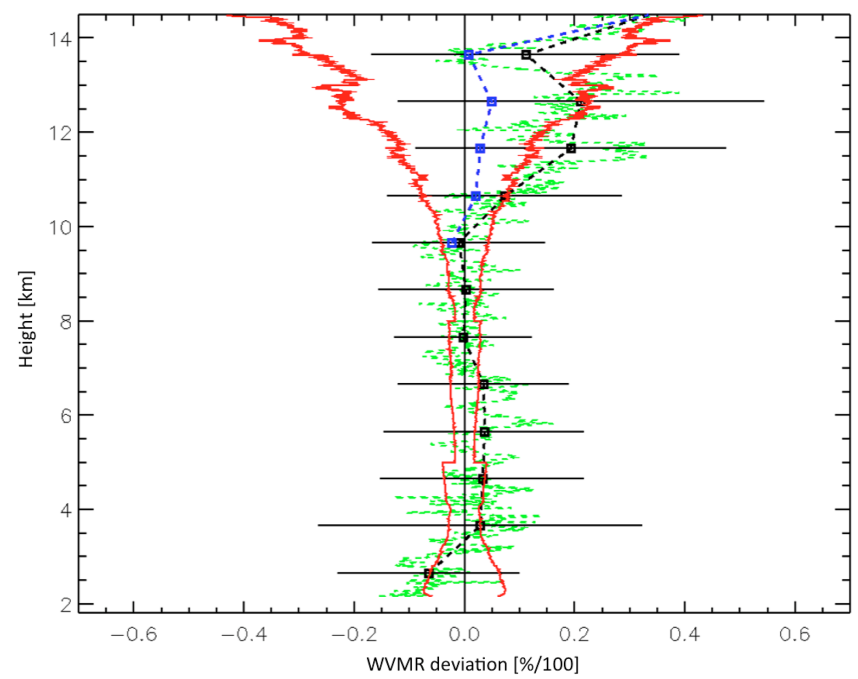

Figure 11. WVMR (lidar-RDS)/RDS relative difference (green dashed curve) between 12 RS92 flights and the 12 corresponding $1 \mathrm{~h}$ integrated lidar profiles acquired during MALICCA. Black squares and horizontal bars depict the relative difference averaged on $1 \mathrm{~km}$ thick layer and its related standard deviation, while the blue squares represent the WVMR relative deviation excluding the lidar-RS92 comparisons of 10 and 11 April. Red curves are the mean lidar statistical error.

the upper troposphere, during MALICCA the launched sondes were, in average, $50 \mathrm{~km}$ distant from the lidar station.

\subsection{UTLS water vapor measurements and uncertainties}

The recent inclusion of the water vapor Raman lidars in NDACC attests the relevance of the technique as a valuable tool to study water vapor in the UTLS. However, in this region, the photon error strongly increases, decreasing the SNR. Thus, to achieve good accuracy, long integration times are required to extend the measurement up to the lower stratosphere (LS). However, this process reduces the variability scale, mixing several geophysical situations that may not exist simultaneously. For the Maïdo station, the proposed observing strategy (determined by the lidar operator availability) is running the lidar $4 \mathrm{~h}$ per night, 2 nights per week. Given these considerations, two different integration methodologies are presented here for the characterization of the UTLS region: nighttime integration and monthly integration. The former approach consists of summing the Raman signals of a typical nighttime lidar acquisition of $240 \mathrm{~min}$, the latter implies the integration of the lidar sessions during a month of regular measurements ( $240 \mathrm{~min} \times 8$ lidar sessions) for a total of approximately $1920 \mathrm{~min}$ of integration.

The result of these two integrations, in terms of the total absolute error ( $\triangle \mathrm{WVMR})$ associated to the calibrated Raman lidar water vapor measurement (WVMR) as a function of different altitudes, are presented in Table 6, where the errors obtained by a standard $120 \mathrm{~min}$ integration are also shown. The $\Delta \mathrm{WVMR}$ has been estimated using the formula obtained by combining Eqs. (1) and (3), and by following Whiteman et 
Table 6. Total absolute ( $\triangle \mathrm{WVMR})$ and relative errors of the calibrated Raman lidar water vapor measurements in the UTLS (between 13 and $20 \mathrm{~km}$ ) for three different data products: $2 \mathrm{~h}$, daily (240 min) and monthly integration.

\begin{tabular}{lllll}
\hline & $\begin{array}{l}\text { 120 min } \\
\text { integration }\end{array}$ & $\begin{array}{l}\text { Nighttime } \\
\text { integration }\end{array}$ & $\begin{array}{l}\text { Monthly } \\
\text { integration }\end{array}$ & \\
\hline $\begin{array}{l}\text { Alt. } \\
(\mathrm{km})\end{array}$ & $\begin{array}{l}\Delta \text { WVMR } \\
(\mathrm{ppmv}, \%)\end{array}$ & $\begin{array}{l}\Delta \text { WVMR } \\
(\mathrm{ppmv}, \%)\end{array}$ & $\begin{array}{l}\Delta \text { WVMR } \\
(\mathrm{ppmv}, \%)\end{array}$ & $\begin{array}{l}\text { Vert. Resol. } \\
(\mathrm{km})\end{array}$ \\
\hline 13 & $3.1(10 \%)$ & $2.6(8 \%)$ & $2.5(8 \%)$ & 0.435 \\
14 & $4.0(23 \%)$ & $2.1(12 \%)$ & $1.5(8 \%)$ & 0.585 \\
15 & $2.5(27 \%)$ & $1.5(16 \%)$ & $0.9(9 \%)$ & 1.005 \\
16 & $4.1(65 \%)$ & $1.5(24 \%)$ & $0.7(10 \%)$ & 2.055 \\
17 & $4.5(110 \%)$ & $2.0(50 \%)$ & $0.6(16 \%)$ & 4.065 \\
18 & - & $2.0(55 \%)$ & $0.5(16 \%)$ & 5.265 \\
19 & - & $3.1(75 \%)$ & $0.9(25 \%)$ & 6.015 \\
20 & - & $3.2(75 \%)$ & $1.0(25 \%)$ & 6.765 \\
\hline
\end{tabular}

al. (2003):

$$
\frac{\Delta \mathrm{WVMR}}{\mathrm{WVMR}}=\sqrt{\left(\frac{\mathrm{d} w}{w}\right)^{2}+\left(\frac{\mathrm{d} C}{C}\right)^{2}+\left(\frac{\mathrm{d} \Gamma_{\Delta}}{\Gamma_{\Delta}}\right)^{2}},
$$

where $\Gamma_{\Delta}$ is the ratio between the total extinction coefficient terms at nitrogen and water vapor Raman wavelengths.

Neglecting in a first approximation the contribution of the extinction term and assuming as $\mathrm{d} C$ the pseudo-standard deviation calculated for the calibration method in Sect. 4.3, it is possible to fully quantify the $\triangle$ WVMR of the Maïdo $\mathrm{H}_{2} \mathrm{O}$ lidar in the UTLS during MALICCA. The results for the single day integrations (i.e., 120 and $240 \mathrm{~min}$ ) are the mean values calculated over the eight sessions that have been also used to simulate the monthly lidar profile.

For a $2 \mathrm{~h}$ integration, the $\triangle \mathrm{WVMR}$ is more than $4 \mathrm{ppmv}$ above $15 \mathrm{~km}$, which corresponds of a total relative error of $65 \%$ and of more than $100 \%$ at $16 \mathrm{~km}$. This confirms the impossibility, with this temporal resolution, of covering the whole troposphere.

On the contrary, the daily integration gives a $\triangle W V M R$ that ranges between 1.5 and 2 ppmv (i.e., a relative error of up to $50 \%$ ) in the upper troposphere (from 15 to $17 / 18 \mathrm{~km}$ ). In this region, recent research (Whiteman et al., 2011b) indicated that random uncertainties of $50 \%$ are acceptable for trend-detection purposes if regular and frequent (e.g., every 3 or 4 days) measurements are taken. Thus, this temporal integration seems to be a good compromise, in terms of accuracy and timescale variability, to study the upper tropospheric water vapor.

The monthly integration approach allows extending the water vapor measurements in the LS. In fact, as illustrated in Table 6, the integration of eight $4 \mathrm{~h}$ lidar sessions (i.e., the number of sessions that would be acquired during a month of regular observations) could lower the $\triangle \mathrm{WVMR}$ to less than $1 \mathrm{ppmv}$ at $20 \mathrm{~km}$, with a relative error kept below $25 \%$. This type of integration could be addressed to the LS, which is characterized by less natural water vapor variability (Hurst et al., 2011a), but more sensitive to additional measurement noise than the upper troposphere. This monthly lower stratospheric water vapor profile might also be useful for the quality control of the data. In fact, as shown by the work of Whiteman et al. (2012), the monthly average water vapor mixing ratios measured by the Microwave Limb Sounder (MLS) can be used to quality control Raman water vapor lidar data. This sounder installed on the AURA satellite observes thermal microwave - far infrared emissions from the Earth's atmosphere in five spectral regions. The water vapor profiles are retrieved from $183 \mathrm{GHz} \mathrm{H} 2 \mathrm{O}$ rotational line spectrum measurements and their precision and accuracy in LS are well documented in literature (Lambert et al., 2007; Vömel et al., 2007b; Livesey et al., 2013).

In our case, the comparison between the campaignintegrated lidar profile and the MLS (version 3.3) mean WVMR profile is depicted in Fig. 12 together with their relative difference (i.e., (MLS-Maido)/Maïdo). The MLS profile is derived by the selection of seven AURA-MLS passages over a $2^{\circ} \times 3^{\circ}$ grid box centered on Réunion island during MALICCA.

Below 16.5-17 km (100 hPa), MLS shows a significant dry bias $(30-40 \%)$. This feature could be caused both by the different instrumental geometry sampling and by the MLS systematic bias in the upper troposphere due to its poor resolution in the very fast transition from dry stratosphere to wet troposphere (Leblanc et al., 2012).

On the contrary, a good agreement is observed in LS between 17 and $20 \mathrm{~km}$ (i.e., 90 and $55 \mathrm{hPa}$ ) with a relative difference of less than $10 \%$ and the lidar profile that falls inside the MLS mean $\pm 2 \sigma$ values. This result confirms the absence of wet biases in the UTLS water vapor lidar profile and validates the value of the calibration coefficient. Above $21 \mathrm{~km}$ $(50 \mathrm{hPa})$, due to the increase of the $\Delta \mathrm{WVMR}$, the lidar water vapor profile is unreliable.

\section{Summary and conclusions}

A new RMR- $\mathrm{H}_{2} \mathrm{O}$ lidar has been installed at the Maïdo altitude station facility of Réunion. The system, designed to ameliorate the critical drawbacks of the previous WV Raman prototype located at St-Denis near sea level, will be devoted to the long-term survey of water vapor in the upper troposphere/lower stratosphere.

The MALICCA campaign, held in April 2013, permitted to optimize the water vapor measurements of the new lidar, to set up a calibration methodology, and to evaluate its performances and capabilities with a particular focus on the UTLS domain.

The optimization of the RMR- $\mathrm{H}_{2} \mathrm{O}$ measurements has been met passing through three phases:

a. Testing the different system configuration scenarios. Regarding the transmitter, the UV emission mode is 

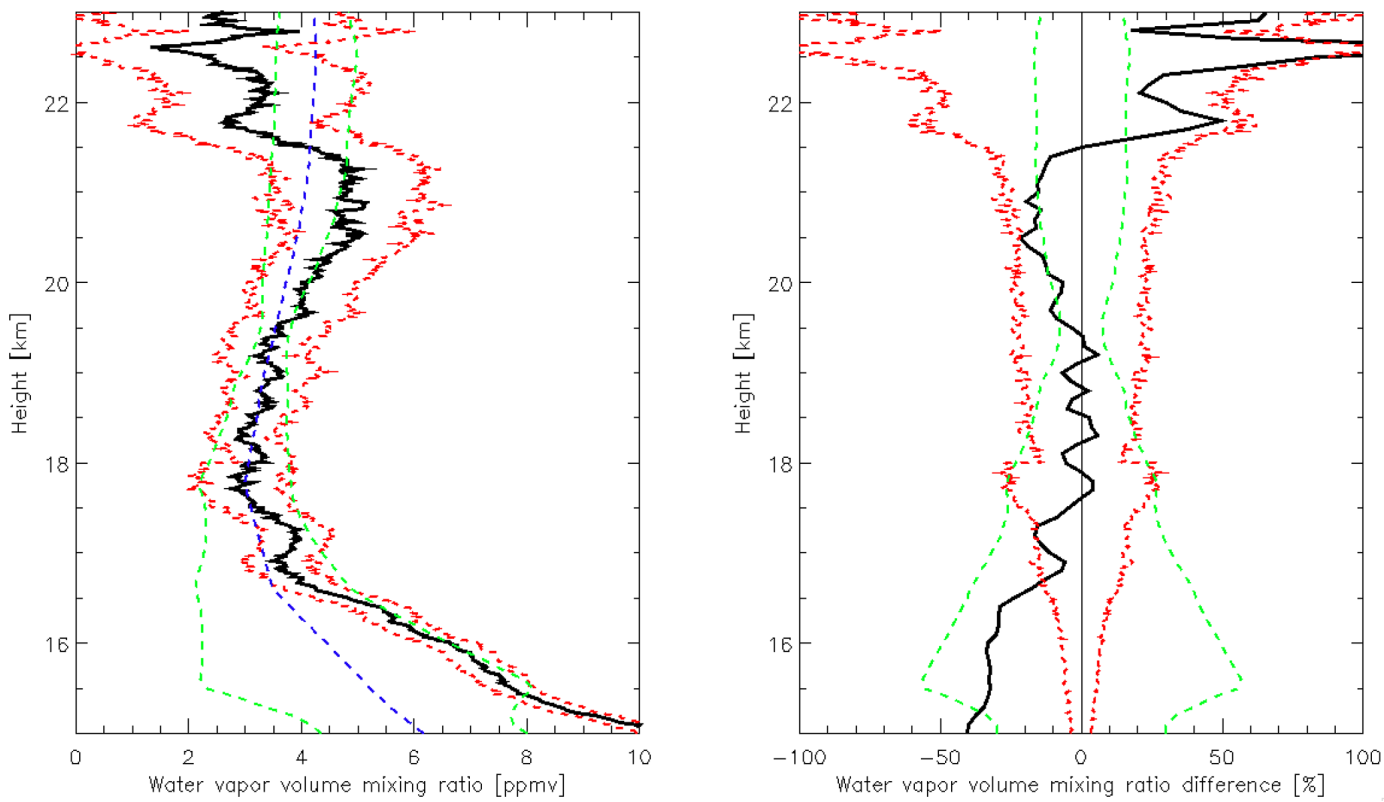

Figure 12. Left plot: UTLS water vapor measurements derived by the lidar campaign-integrated profile (black line) and by the MLS average profile calculated during MALICCA (blue dashed line). Red dotted curves are the associated total lidar error, while green dashed lines represent the mean $\pm 2-\sigma$ of the MLS profile. Right plot: relative difference, $100 \times($ MLS-Maïdo)/Maïdo, between the lidar and the MLS UTLS water vapor measurement (black line), together with the associated lidar uncertainty and the 2- $\sigma$ MLS profiles (red dotted and green dashed curves, respectively).

preferable to the visible one in terms of the maximum heights reached by the SNR and the detectability; doubling the emitted power (i.e., coupling two lasers) increases the SNR, but also the background noise and the saturation effect of the PMT in the nitrogen Raman channel. For the receiver, the fields of view of 0.55 and $0.69 \mathrm{mrad}$ are those that better satisfy the constraints of the SNR and the linearity response of the PMTs.

b. Verifying the presence of possible parasitic signals. Mostly, the absence of a distinguishable fluorescent contamination in the Raman water vapor channel has been verified measuring the signal at $432 \mathrm{~nm}$, a spectral region where there is a negligible backscatter contribution from atmospheric constituents. Additionally, the nominal OD of the Raman $\mathrm{H}_{2} \mathrm{O}$ channel (15 and 9 , at 355 and $387 \mathrm{~nm}$, respectively) seems to guarantee a correct rejection to the signal contamination due to the Rayleigh, Mie or Raman nitrogen signals. This has been confirmed by comparing the water vapor mixing ratio profiles measured by the lidar and the co-located RS92 radiosondes in correspondence of a cirrus layer. No evidence of signal leakage into the water vapor Raman channel has been detected.

c. Determining the height dependence of the lidar statistical error. The lidar performances measured during MALICCA have been compared to those simulated by Hoareau et al. (2012). The mean altitudes above the sea level where the $\mathrm{H}_{2} \mathrm{O}$ measurements have a relative statistical error per bin within 15 and $30 \%$ are 12.3 and $13.4 \mathrm{~km}$, respectively. These quotes are 1.7 and $2.9 \mathrm{~km}$ lower than those estimated by the lidar simulation. Applying an height-dependent sliding average to the lidar raw data, with a temporal integration of 30 and $120 \mathrm{~min}$, limits the statistical error to less than $10 \%$ below $13 \mathrm{~km}$, maintaining a high vertical resolution in the lower and the middle troposphere. Above $13 \mathrm{~km}$ the vertical resolution gradually degrades with random errors equal to more than $50 \%$ at $16 \mathrm{~km}$.

Since one of the overall goals of the RMR- $\mathrm{H}_{2} \mathrm{O}$ Maïdo lidar is to provide long-term monitoring, a hybrid calibration methodology has been set up and validated to insure optimal lidar calibration stability with time. The receiver transmittance is monitored through the calibration lamp method that, at the moment, can detect transmittance variations greater than $10-15 \%$. The calibration coefficients are then calculated through the hourly values of IWV provided by the colocated GPS. The comparison between the calibration constants derived by the GPS and the Vaisala RS92 radiosondes launched at Maïdo during MALICCA, points out an acceptable agreement in terms of accuracy of the mean calibration value (with a difference of approximately $2-3 \%$ ), but a significant difference in terms of variability (14\% versus $7-9 \%$, for GPS and RS92 calibration procedures, respectively). Further studies are needed to characterize these dissimilarities, which can be partly explained by the sampling difference of 
the considered instruments (i.e., lidar, GPS and radiosonde) that is stressed by the high and local variation of water vapor regimes on Réunion island. However, the higher variability of IWV GPS strategy is balanced by the possibility of having a greater number of samples during a lidar session.

During MALICCA, the lidar measurements have been compared to 15 co-located and simultaneous RS92 radiosondes. A relatively good agreement between the instruments (i.e., relative difference below 10\%) is measured in the low and the middle troposphere $(2-10 \mathrm{~km})$. The upper troposphere (up to $15 \mathrm{~km}$ ) is characterized by a larger spread (approximately $20 \%$ ), which lowers below $10 \%$ by excluding from the statistics the nights of 10 and 11 April. This result confirms that, at high altitudes and depending on the water vapor spatial distribution, the distance of the two sensors can significantly affect the comparison between lidar and radiosoundings.

To measure the water vapor in the UTLS region two different integration methodologies have been adopted: nighttime integration and monthly integration. The former, which consists of a temporal integration of $240 \mathrm{~min}$, allows measuring the WVMR in the UT (up to $17 / 18 \mathrm{~km}$ ) with an absolute uncertainty of 2 ppmv. The latter, obtained simulating a month of regular measurements ( $240 \mathrm{~min} \times 8$ lidar sessions), allows extending the measurements in the lower stratosphere, lowering the absolute error to $1 \mathrm{ppmv}$ at $20 \mathrm{~km}$.

Finally, the comparison between the lidar monthly profile and the mean WVMR profile measured by MLS can be used as a quality control procedure of the lidar product. Following Whiteman et al. (2012), the good agreement observed in the lower stratosphere (from 17 to $20 \mathrm{~km}$ ) attests the absence of significant wet biases and validates the calibration procedure.

In conclusion, the design and the performance of this new lidar system permit the covering of a large altitude range from the ground up to the lower stratosphere (19-20 km). In particular, the obtained results show the capabilities of the $\mathrm{H}_{2} \mathrm{O}$ lidar to measure water vapor in UTLS down to few ppmv with random errors around 50 and $25 \%$ accordingly to the adopted integration scheme. The achievement of this objective opens up new opportunities for the characterization of the water vapor in this atmospheric region, in terms of long-term monitoring, process investigation and instrumental inter-comparison and satellite validation. Within this frame, further testing is planned to optimize the calibration procedure, with the goal of increasing the accuracy and stability of the method. In the near future, to use the MAIDO $\mathrm{H}_{2} \mathrm{O}$ lidar as a reference instrument in the southern subtropics, it will be crucial to improve the data quality testing, implementing operational procedures to characterize the measurements and minimize the influence of systematic errors.

Acknowledgements. The research leading to these results has received funding from the European Union Seventh Framework Programme (FP7/2007-2013), the University of Versailles and Saint-Quentin in Yvelines (UVSQ) under grant agreement RBUCE-UP $\mathrm{N}^{\circ} 246556$, the CNRS-INSU through the annual support of the NDACC Observing Service; the Alliance AllEnvi through the ROSEA project (French initiative from the ALLENVI structure dedicated to observation and investigation of atmospheric water). RS92 were launched thanks to the cooperative Vaisala receiver provided by GMEI/4M group of the CNRM (CNRS-Météo-France). The authors acknowledge the European Communities, the Région Réunion, CNRS, and Université de La Réunion for their support and contribution in the construction phase of the research infrastructure OPAR (Observatoire de Physique de l'Atmosphère à La Réunion). OPAR is presently funded by CNRS (INSU) and Université de La Réunion, and managed by OSU-R (Observatoire des Sciences de l'Univers à la Réunion, UMS 3365). The authors are very grateful to Holger Vömel and Michael Sommers for providing the correction to the Vaisala RS92 launched during MALICCA and to Sergey Khaykin for the analysis of the MLS mean WVMR profile.

Edited by: R. Sussmann

\section{References}

Baray, J. L., Leveau, J., Baldy, S., Jouzel, J., Keckhut, P., Bergametti, G., Ancellet, G., Bencherif, H., Cadet, B., Carleer, M., David, C., De Mazière, M., Faduilhe, D., Godin-Beekmann, S., Goloub, P., Goutail, F., Metzger, J. M., Morel, B., Pommereau, J.P., Porteneuve, J., Portafaix, T., Posny, F., Robert, L., and Van Roozendael, M.: An instrumented station for the survey of ozone and climate change in the southern tropics: Scientific motivation, technical description and future plans, J. Environm. Monit., 8, 1020-1028, 2006.

Baray, J.-L., Courcoux, Y., Keckhut, P., Portafaix, T., Tulet, P., Cammas, J.-P., Hauchecorne, A., Godin Beekmann, S., De Mazière, M., Hermans, C., Desmet, F., Sellegri, K., Colomb, A., Ramonet, M., Sciare, J., Vuillemin, C., Hoareau, C., Dionisi, D., Duflot, V., Vérèmes, H., Porteneuve, J., Gabarrot, F., Gaudo, T., Metzger, J.-M., Payen, G., Leclair de Bellevue, J., Barthe, C., Posny, F., Ricaud, P., Abchiche, A., and Delmas, R.: Maïdo observatory: a new high-altitude station facility at Reunion Island $\left(21^{\circ} \mathrm{S}, 55^{\circ} \mathrm{E}\right)$ for long-term atmospheric remote sensing and in situ measurements, Atmos. Meas. Tech., 6, 2865-2877, doi:10.5194/amt-6-2865-2013, 2013.

Bevis, M., Businger, S., Herring, T., Rocken, C., Anthes, R. A., and Ware, R. H.: GPS meteorology: Remote sensing of the atmospheric water vapor using the global positioning system. J. Geophys. Res., 97, 15787-15801, 1992.

Bock, O., Doerflinger, E., Masson, F., Walpersdorf, A., Van Baelen, J., Tarniewicz, J., Troller, M., Somieski, A., Geiger, A., and Bürki, B.: GPS water vapor project associated to the ESCOMPTE programme: description and first results of the field experiment, Phys. Chem. Earth, 29, 149-157, 2004.

Bock, O., Bosser, P., Bourcy, T., David, L., Goutail, F., Hoareau, C., Keckhut, P., Legain, D., Pazmino, A., Pelon, J., Pipis, K., Poujol, G., Sarkissian, A., Thom, C., Tournois, G., and Tzanos, D.: Accuracy assessment of water vapour measurements from in situ and remote sensing techniques during the DEMEVAP 2011 cam- 
paign at OHP, Atmos. Meas. Tech., 6, 2777-2802, 2013, http://www.atmos-meas-tech.net/6/2777/2013/.

Dinoev, T., Simeonov, V., Arshinov, Y., Bobrovnikov, S., Ristori, P., Calpini, B., Parlange, M., and van den Bergh, H.: Raman Lidar for Meteorological Observations, RALMO - Part 1: Instrument description, Atmos. Meas. Tech., 6, 1329-1346, doi:10.5194/amt-6-1329-2013, 2013.

Dionisi, D., Congeduti, F., Liberti, G. L., and Cardillo, F.: Calibration of a Multichannel Water Vapor Raman Lidar through Noncollocated Operational Soundings: Optimization and Characterization of Accuracy and Variability, J. Atmos. Ocean. Technol., 27, 108-121, 2010.

Dirksen, R. J., Sommer, M., Immler, F. J., Hurst, D. F., Kivi, R., and Vömel, H.: Reference quality upper-air measurements: GRUAN data processing for the Vaisala RS92 radiosonde, Atmos. Meas. Tech., 7, 4463-4490, doi:10.5194/amt-7-4463-2014, 2014.

Durry, G. and Pouchet, I.: A near-infrared diode laser spectrometer for the in situ measurement of methane and water vapor from stratospheric balloons. J. Atmos. Oceanic Technol., 18, 14851494, 2001.

Emardson, T. R. and Derks, H. J. P.: On the relation between the wet delay and the integrated precipitable water vapour in the European atmosphere, Meteor. Appl., 6, 1-12, 1999.

Ferrare, R. A., Melfi, S. H., Whiteman, D. N., Evans, K. D., Schmidlin, F. J., and Starr, D. O'C.: A comparison of water vapor measurements made by Raman lidar and radio- sondes. J. Atmos. Oceanic Technol., 12, 1177-1195, 1995.

Foelsche, U. and Kirchengast, G.: Tropospheric water vapor imaging by combination of ground-based and spaceborne GNSS sounding data, J. Geophys. Res., 106, 27221-27231, 2001.

Goldsmith, J. E. M., Blair, F. H., Bisson, S. E., and Turner, D. D.: Turnkey Raman lidar for profiling atmospheric water vapor, clouds, and aerosols., Appl. Opt., 37, 4979-4990, 1998.

Hauchecorne, A., Chanin, M. L., and Keckhut, P.: Climatology and trends of the middle atmospheric temperature $(33-87 \mathrm{~km})$ as seen by Rayleigh lidar over the south of France, J. Geophys. Res., 96, 15297-15309, 1991.

Hyland, R. W. and Wexler, A.: Formulations for the thermodynamic properties of the saturated phases of $\mathrm{H} 2 \mathrm{O}$ from $173.15 \mathrm{~K}$ to $473.15 \mathrm{~K}$, ASHRAE Tran., 89, 500-519, 1983.

Hoareau, C., Keckhut, P., Baray, J.-L., Sarkissian, A., and Durry, G.: Methodology for water monitoring in the upper troposphere with Raman lidar at Observatory of Haute-Provence, J. Atmos. Ocean. Technol., 26, 2149-2160, 2009.

Hoareau, C., Keckhut, P., Baray, J.-L., Robert, L., Courcoux, Y., Porteneuve, J., Vömel, H., and Morel, B.: A Raman lidar at La Reunion $\left(20.8^{\circ} \mathrm{S}, 55.5^{\circ} \mathrm{E}\right)$ for monitoring water vapour and cirrus distributions in the subtropical upper troposphere: preliminary analyses and description of a future system, Atmos. Meas. Tech., 5, 1333-1348, doi:10.5194/amt-5-1333-2012, 2012.

Hurst, D. F., Oltmans, S. J., Vömel, H., Rosenlof, K. H., Davis, S. M., Ray, E. A., Hall, E. G., and Jordan, A. F.: Stratospheric water vapor trends over Boulder, Colorado: Analysis of the 30 year Boulder record, J. Geophys. Res., 116, D02306, doi:10.1029/2010JD015065, 2011a.

Immler, F. J., Dykema, J., Gardiner, T., Whiteman, D. N., Thorne, P. W., and Vömel, H.: Reference Quality Upper-Air Measurements: guidance for developing GRUAN data products, Atmos. Meas. Tech., 3, 1217-1231, doi:10.5194/amt-3-1217-2010, 2010.
Jensen, E. J., Kinne, S., and Toon, O. B.: Tropical cirrus clouds radiative forcing: Sensitivity studies, Geophys. Res. Lett., 21, 2023-2026, 1994.

Kämpfer, N. (Ed.): Monitoring Atmospheric Water Vapour: Ground-Based Remote Sensing and In-situ Methods, International Space Science Institute, Bern (Switzerland), ISSI Scientific Reports Series, Vol. 10, ISBN 978-1-4614-3908-0, Springer, Berlin, Heidelberg, New York, 2012.

Keckhut, P., Courcoux, Y., Baray, J.-L., Porteneuve, J., Vérèmes, H., Hauchecorne, A., Dionisi, D., Posny, F., Cammas, J.-P., Payen, G., Gabarrot, F., Evan S., Khaykin, S., Rüfenacht, R., Tschanz, B., Kämpfer, N., Ricaud, Ph., Abchiche, A., Leclair-de-Bellevue, J., and Duflot, V.: Thermodynamic upper air observations at La Réunion during the MALICCA campaign, J. Appl. Remote Sens., submitted, 2015.

Kiehl, J. T. and Trenberth, K. E.: Earth's annual global mean energy budget, B. Am. Meteor. Soc., 78, 197-208, 1997.

Kiemle, C., Wirth, M., Fix, A., Ehret, G., Schumann, U., Gardiner, T., Schiller, C., Sitnikov, N., and Stiller, G.: First airborne water vapour lidar measurements in the tropical upper troposphere and mid-latitudes lower stratosphere: accuracy evaluation and intercomparisons with other instruments, Atmos. Chem. Phys., 8, 5245-5261, doi:10.5194/acp-8-5245-2008, 2008.

King, R. and Bock, Y.: Documentation for the GAMIT GPS analysis software, Release 10.32. Mass. Inst. Technol., Cambridge, 2007.

Kley, D., Russell III, J. M., and Phillips, C.: SPARC (Stratospheric Processes And their Role in Climate) Assessment of Upper Tropospheric and Stratospheric Water Vapour, WCRP-113, WMO/TD No. 1043, SPARC Report No. 2, 2000.

Lambert, A., Read, W. G., Livesey, N. J., Santee, M. L., Manney, G. L., Froidevaux, L., Wu, D. L., Schwartz, M. J., Pumphrey, M., Jimenez, C., Nedoluha, G. E., Cofield, R. E., Cuddy, D. T., Daffer, W. F., Drouin, B. J., Fuller, R. A., Jarnot, R. F., Knosp, B. W., Pickett, H. M., Perun, V. S., Snyder, W. V., Stek, P. C., Thurstans, R. P., Wagner, P. A., Waters, J. W., Jucks, K. W., Toon, G. C., Stachnik, R. A., Bernath, P. F., Boone, C. D., Walker, K. A., Urban, J., Murtagh, D., Elkins, J. W., and Atlas, E.: Validation of the Aura Microwave Limb Sounder middle atmosphere water vapor and nitrous oxide measurements, J. Geophys. Res., 112, D24S36, doi:10.1029/2007JD008724, 2007.

Leblanc, T. and McDermid, I. S.: Reply to "Comments on Accuracy of Raman lidar water vapour calibration and its applicability to long-term measurements" by Whiteman et al., Appl. Opt., 50, 2177-2178, 2011.

Leblanc, T., McDermid, I. S., and Raspey, R. A.: First-year operation of a new water vapour Raman lidar at the JPL Table Mountain Facility, California, J. Atmos. Ocean. Technol., 25, 1454 1462, 2008.

Leblanc, T., McDermid, I. S., and Walsh, T. D.: Ground-based water vapor Raman lidar measurements up to the upper troposphere and lower stratosphere for long-term monitoring, Atmos. Meas. Tech., 5, 17-36, doi:10.5194/amt-5-17-2012, 2012.

Lesouëf, D., Gheusi, F., Chazette, P., Delmas, R., Sanak, J.: Low Tropospheric Layers Over Reunion Island in Lidar-Derived Observations and a High-Resolution Model, Bound.-Lay. Meteorol., 149, 425-453, 2013.

Livesey, N. J., Read, W. G., Froidevaux, L., Lambert, A., Manney, G. L., Pumphrey, H. C., Santee, M. L., Schwartz, M. J., Wang, 
S., Cofield, R. E., Cuddy, D. T., Fuller, R. A., Jarnot, R. F., Jiang, J. H., Knosp, B. W., Stek, P. C., Wagner, P. A., and Wu, D. L.: Version 3.3 and 3.4 level 2 data quality and description document, available at: http://mls.jpl.nasa.gov/data/v3_data_quality_ document.pdf (last access: March 2015), Jet Propulsion Laboratory/California Institute of Technology, JPL, 33509, 65 pp., 2013.

Melfi, S. H.: Remote measurements of the atmosphere using Raman scattering. Appl. Opt., 11, 1288-1292, 1972.

Melfi, S. H., Lawrence, J. D., and McCormic, Mp.: Observation of Raman Scattering by Water Vapor in Atmosphere, Appl. Phys. Lett., 15, 295-297, doi:10.1063/1.1653005, 1969.

Melfi, S. H., Evans, K., Li, J., Whiteman, D., Ferrare, R., and Schwemmer, G.: Observation of Raman scattering by cloud droplets in the atmosphere, Appl. Opt., 36, 3551-3559, 1997.

Miloshevich, L. M., Vömel, H., Whiteman, D., Lesht, B., Schmidlin, F. J., and Russo, F.: Absolute accuracy of water vapor measurements from six operational radiosondes types launched during AWEX-G and implications for AIRS validation, J. Geophys. Res., 111, D09S10, doi:10.1029/2005JD006083, 2006.

Miloshevich, L. M., Vömel, H., Whiteman, D. N., and Leblanc, T.: Accuracy assessment and correction of Vaisala RS92 radiosonde water vapor measurements, J. Geophys. Res., 114, D11305, doi:10.1029/2008JD011565, 2009.

Nedeljkovic, D., Hauchecorne, A., and Chanin, M.-L.: Rotational Raman lidar to measure the atmospheric temperature from ground to $30 \mathrm{~km}$, IEEE Trans. Geosci. Remote Sens., 31, 90101, 1993.

Niell, A. E., Coster, A. J., Solheim, F. S., Mendes, V. B., Toor, P. C., Langley, R. B., and Upham, C. A.: Comparison of measurements of atmospheric wet delay by radiosonde, water vapor radiometer, GPS, and VLBI, J. Atmos. Ocean Tech., 18, 830-850, 2001.

Oltmans, S. J. and Hofmann D. J.: Increase in lower-stratospheric water vapor at a mid-latitude Northern Hemisphere site from 1981 to 1994, Nature, 374, 146-149, 1995.

Osterman, G. B., Salawitch, R. J., Sen, B., Toon, G. C., Stachnik, R. A., Pickett, H. M., Margitan, J. J., Blavier, J.-F., and Peterson, D. B.: Balloon-borne measurements of stratospheric radicals and their precursors: Implications for the production and loss of ozone, Geophys. Res. Lett., 24, 1107-1110, 1997.

Penney, C. M. and Lapp, M.: Raman-scattering cross sections for water vapor. J. Opt. Soc. Amer., 66, 422-425, 1976.

Reichardt, J., Wandinger, U., Klein, V., Mattis, I., Hilber, B., and Begbie, R.: RAMSES: the German Meteorological Service autonomous Raman lidar for water vapor, temperature, aerosol, and cloud measurements, Appl. Opt., 51, 8111-8131, 2012.

Saastamoinen, J.: Atmospheric correction for the troposphere and stratosphere in radio ranging of satellites. Geophys. Monogr. Ser. 15, edited by: S. W. Henriksen, 247-251, 1972.

Sakai, T., Nagai, T., and Nakazato, M.: Comparisons of Raman lidar measurements of tropospheric water vapour profiles with radiosondes, Hygrometers on the Meteorological Observation Tower, and GPS at Tsukuba, Japon, J. Atmos. Ocean. Technol., 24, 1407-1423, 2007.

Salasmaa, E. and Kostamo, P.: New thin film humidity sensor, in: Proc. of Third Symposium on Meteorological Observations and Instrumentation, Washington, DC, Am. Meteor. Soc., 33-38, 1975.
Sherlock, V., Garnier, A., Hauchecorne, A., and Keckhut, P.: Implementation and validation of a Raman lidar measurement of middle and upper tropospheric water vapour. Appl. Opt., 38, 58385850, 1999a.

Sherlock, V. J., Hauchecorne, A., and Lenoble, J.: Methodology for the independent calibration of Raman backscatter water vapour lidar systems, Appl. Opt., 38, 5816-5837, 1999b.

Simeonov, V., G. Larcheveque, P. Quaglia, H. van den Bergh, and Calpini, B.: Influence of the photo- multiplier tube spatial uniformity on lidar signals, Appl. Opt., 38, 24, 5186-5190, 1999.

Singh, U. N., Keckhut, P., McGee, T. J., Gross, M. R., Hauchecorne, A., Fishbein, E. F., Waters, J. W., Gille, J. C., Roche, A. E., and Russell III, J. M.: Stratospheric temperature measurements by two collcated NDSC lidars at OHP during UARS validation campaign, J. Geophys. Res., Special Issue on UARS Data Validation, 101, 10287-10298, 1996.

Sherwood, C. S. and Dessler., A.: On the control of stratospheric humidity, Geophys. Res. Lett., 16, 2513-2516, 2000.

Suortti, T. M., Kats, A., Kivi, R., Kämpfer, N., Leiterer, U., Miloshevich, L. M., Neuber, R., Paukkunen, A., Rup- pert, P., Vömel, H., and Yushkov, V.: Tropospheric Com- parisons of Vaisala Radiosondes and Balloon-Borne Frost-Point and Lyman- $\alpha$ Hygrometers during the LAUTLOS- WAVVAP Experiment, J. Atmos. Oceanic Tech., 25, 149-166, 2008.

Vaughan, G., Wareing, D. P., Thomas, L., and Mitev, V.: Humidity measurements in the free troposphere using Raman backscatter. Quart. J. Roy. Meteor. Soc., 114, 1471-1484, 1988.

Vogelmann, H., Sussmann, R., Trickl, T., and Borsdorff, T.: Intercomparison of atmospheric water vapor soundings from the differential absorption lidar (DIAL) and the solar FTIR system on Mt. Zugspitze, Atmos. Meas. Tech., 4, 835-841, doi:10.5194/amt-4-835-2011, 2011.

Vömel, H., David, D. E., and Smith, K.: Accuracy of tropospheric and stratospheric water vapor measurements by the cryogenic frost point hygrometer: Instrumental details and observations, J. Geophys. Res., 112, D08305, doi:10.1029/2006jd007224, 2007a.

Vömel, H., Barnes, J. E., Forno, R. N., Fujiwara, M., Hasebe, F., Iwasaki, S., Kivi, R., Komala, N., Kyro, E., Leblanc, T., Morel, B., Ogino, S.-Y., Read, W. G., Ryan, S. C., Saraspriya, S., Selkirk, H., Shiotani, M., Valverde Canossa, J., and Whiteman, D. N.: Validation of Aura Microwave Limb Sounder water vapor by balloonborne Cryogenic Frost point Hygrometer measurements, J. Geophys. Res., 112, D24S37, doi:10.1029/2007JD008698, 2007b.

Wennberg, P.O., Cohen, R. C., Stimpfle, R. M., Koplow, J. P., Anderson, J. G., Salawitch, R. J., Fahey, D. W., Woodbridge, E. L., Keim, E. R., Gao, R. S., Webster, C. R., May, R. D., Toohey, D. W., Avallone, L. M., Proffitt, M. H., Loewenstein, M., Podolske, J. R., Chan, K. R., and Wofsy, S. C.: Removal of stratospheric $\mathrm{O}_{3}$ by radicals: In-situ measurements of $\mathrm{OH}, \mathrm{HO}_{2}, \mathrm{NO}, \mathrm{NO}_{2}, \mathrm{ClO}$ and BrO, Science, 266, 398-404, 1994.

Whiteman, D., Melfi, S. H., and Ferrare, R. A.: Raman lidar system for the measurements of water vapor and aerosols in the Earth's atmosphere, Appl. Opt., 42, 3068-3082, 1992.

Whiteman, D. N.: Examination of the traditional Raman lidar technique. II. Evaluating the ratios for water vapor and aerosols, Appl. Opt., 42, 2593-2608, 2003. 
Whiteman, D. N., Demoz, B., Di Girolamo, P., Comer, J., Veselovskii, I., Evans, K., Wang, Z., Cadirola, M., Rush, K., Schwemmer, G., Gentry, B., Melfi, S. H., Mielke, B., Venable, D., and Van Hove, T.: Raman water vapour lidar measurements during the International $\mathrm{H}_{2} \mathrm{O}$ Project. I. Instrumentation and analysis techniques, J. Atmos. Ocean. Technol. 23, 157-169, 2006.

Whiteman, D. N., Veselovskii, I., Cadirola, M., Rush, K., Comer, J., Potter, J. R., and Tola, R.: Demonstration measurements of water vapor, cirrus clouds, and carbon dioxide using a high- performance Raman lidar, J. Atmos. Ocean. Tech., 24, 1377-1388, 2007.

Whiteman, D. N., Rush, K., Rabenhorst, S., Welch, W., Cadirola, M., McIntire, G., Russo, F., Adam, M., Venable, D., Connell, R., Veselovski, I., Forno, R., Mielke, B., Stein, B., Leblanc, T., McDermid, S., and Vömel, H.: Airborne and Ground-based measurements using a High-Performance Raman Lidar, J. Atmos. Ocean. Technol., 27, 1781-1801, 2010.
Whiteman, D. N., Venable, D., and Landulfo, E.: Comments on: accuracy of Raman lidar water vapour calibration and its applicability to long-term measurements, Appl. Opt., 50, 2170-2176, 2011a.

Whiteman, D. N., Vermeesch, K. C., Oman, L. D., and Weather, E. C.: The relative importance of random error and observation frequency in detecting trends in upper tropospheric water vapour, J. Geophys. Res., 116, D21118, doi:10.1029/2011JD016610, $2011 b$.

Whiteman, D. N., Cadirola, M., Venable, D., Calhoun, M., Miloshevich, L., Vermeesch, K., Twigg, L., Dirisu, A., Hurst, D., Hall, E., Jordan, A., and Vömel, H.: Correction technique for Raman water vapor lidar signal-dependent bias and suitability for water vapor trend monitoring in the upper troposphere, Atmos. Meas. Tech., 5, 2893-2916, doi:10.5194/amt-5-2893-2012, 2012. 